\title{
Beta-Amino Phosphine Mn Catalysts for 1,4-Transfer Hydrogena- tion of Chalcones and Allylic Alcohol Isomerization
}

\author{
Vipulan Vigneswaran and David C. Lacy* \\ Department of Chemistry, University at Buffalo, SUNY, Buffalo, New York 14260-3000, United States.
}

\section{Supporting Information Placeholder}

\begin{abstract}
Mn complexes with amino acid-derived PN ligands were used to enact catalytic transfer hydrogenation $(\mathrm{TH})$ of ketone and chalcone substrates in 2-proponal with mild heating. Moreover, chalcones are reduced selectively to the saturated ketone at short times and can be fully converted to the alcohol under prolonged reactions. The mechanism of chalcone reduction was briefly considered. Allylic alcohols are not reactive in 2-proponal, but quantitative isomerization occurs in toluene. Thus, we suspect that the allylic alcohols are dehydrogenated and the resulting ketone is formed through a direct 1,4-hydrogenation of the chalcone. Finally, several other related ligands that have been used in Mn-based TH reactions were explored to test the viability of ligand design in favoring chemoselectivity. The beta-amino phosphine ligands proved most effective in this regard.
\end{abstract}

Transfer hydrogenation and dehydrogenation (TH \& $\mathrm{TdH}$ ) are incredibly important transformations in organic synthesis, and the field has been described as experiencing a "golden age". ${ }^{1}$ Despite the large number of metal ions that have been found to carry out $\mathrm{TH}$, the first manganese(I) TH catalysts were only discovered recently. ${ }^{2-7}$ Some of these catalysts use phosphine-free ligands ${ }^{4-7}$ and asymmetric catalysis has been achieved in some instances. ${ }^{3,4}$

The ever-expanding versatility and unique properties of $\mathrm{Mn}(\mathrm{I})$ based catalysts is nicely demonstrated by the fact that $\mathrm{Mn}(\mathrm{I})$ catalysts are supported with bidentate ligands more effectively than iron and ruthenium. ${ }^{8}$ For instance, Pidko and Beller ${ }^{9}$ recently disclosed the use of beta-amino glycine derived phosphine ligands in hydrogenation reactions and Khusnutdinova ${ }^{10}$ used bipyridinebased ligands in TH reactions. While it is commendable that many $\mathrm{Mn}(\mathrm{I})$ catalyzed $\mathrm{TH}$ studies can use cheap, phosphine-free ligands, the exclusion of strong field supporting ligands destabilizes the low-spin $d^{6}$ configuration resulting in facile electron transfer decompositions to unreactive $\mathrm{Mn}(\mathrm{II})$ species.
Herein, we expand on Pidko and Beller's findings that beta-amino phosphine ligands are excellent supports for $\mathrm{TH} \& \mathrm{TdH} \mathrm{Mn}(\mathrm{I})$ catalysts. One motivation for us was that beta-amino phosphines can be derived from cheap amino acid feedstocks in addition to the relative low-price of $\mathrm{HPPh}_{2}$ compared to other phosphine precursors and therein produced on large scales. In this report, we demonstrate that beta-amino phosphine derived from phenylglycine coordinated to $\mathrm{Mn}(\mathrm{I})$ ions are efficient catalysts for ketone $\mathrm{TH}, 1,4$ chalcone reductions, and allylic alcohol isomerization. The $\mathrm{Mn}(\mathrm{I})$ catalysts exhibit exceptional functional group tolerance and rapidly achieve high conversions under mild conditions $\left(60^{\circ} \mathrm{C}, 3\right.$ hours).

For this work, we prepared PN ligands derived from the amino acid glycine, phenylglycine, and phenylalanine. The general procedure is one adapted from a variety of literature sources. This entails a simple reduction of the amino acid to the alcohol ${ }^{11}$ and subsequent cyclization to the oxazolidine, ${ }^{12}$ the latter of which is converted into the free ligand $\mathbf{H L}^{\mathbf{R}}(\mathrm{R}=\mathrm{H}, \mathrm{Ph}, \mathrm{Bz})$ by addition of triflic acid and diphenyl phosphine (Scheme 1). ${ }^{13}$ The glycine- and phenylalanine-derived ligands are liquids, whereas the phenylglycine-derived PN ligand $\mathbf{H L}^{\mathbf{P h}}$ is a white solid and easy to work with. Hence, the phenylglycine-derived $\mathrm{PN}$ ligand $\mathbf{H L}^{\mathrm{Ph}}$ was used for the reactions below.

Scheme 1. Ligand and Catalyst Synthesis

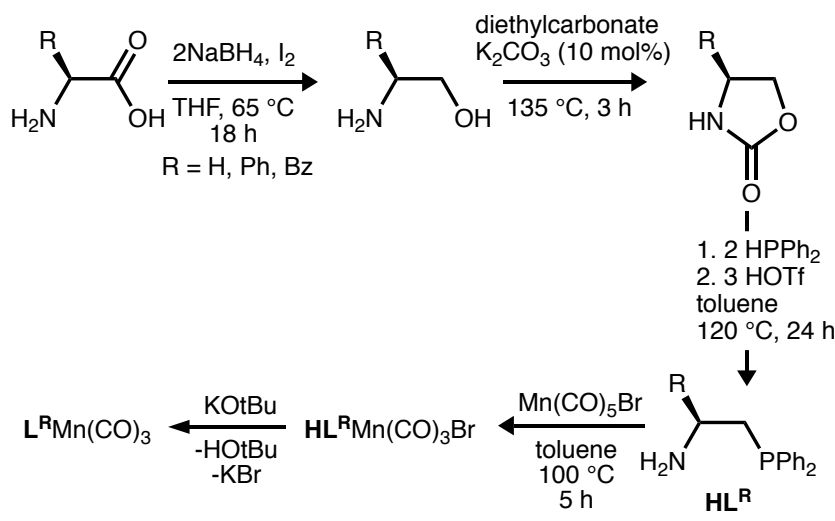


Coordination of the $\mathrm{Mn}(\mathrm{I})$ was accomplished by treatment of the free ligand $\mathbf{H L}^{\mathbf{P h}}$ with $\mathrm{Mn}(\mathrm{CO})_{5} \mathrm{Br}$ in toluene and heating to $100{ }^{\circ} \mathrm{C}$ for $10-12$ hours in a sealed Schlenk bomb. The material can be recovered by removal of solvent and recrystallized from THF and petroleum ether to afford crystalline precatalyst $\mathbf{H L}^{\mathrm{Ph}} \mathrm{Mn}(\mathrm{CO})_{3} \mathrm{Br}$ in good yields ( $>80 \%$ crystalline). The ${ }^{31} \mathrm{P}-\mathrm{NMR}$ spectrum of crystalline $\mathbf{H L}^{\mathrm{Ph}} \mathrm{Mn}(\mathrm{CO})_{3} \mathrm{Br}$ in $\mathrm{CD}_{2} \mathrm{Cl}_{2}$ contains a single peak $\left({ }^{31} \mathrm{P}\left\{{ }^{1} \mathrm{H}\right\}\right.$ NMR $\left.=53 \mathrm{ppm}\right)$. Treatment of the crystalline precatalyst $\mathbf{H L}^{\mathrm{Ph}} \mathrm{Mn}(\mathrm{CO})_{3} \mathrm{Br}$ with $\mathrm{KO}^{t} \mathrm{Bu}$ in toluene affords an amber-brown species tentatively assigned as the $\mathbf{L}^{\mathbf{P h}} \mathrm{Mn}(\mathrm{CO})_{3} 16-\mathrm{e}^{-}$catalyst $\left({ }^{31} \mathrm{P}\left\{{ }^{1} \mathrm{H}\right\}\right.$ NMR $=72 \mathrm{ppm}$ ), but this material was not isolated or characterized further.

\section{Scheme 2. Transfer Hydrogenation Functional Group Tolerance (Isolated Yields)}
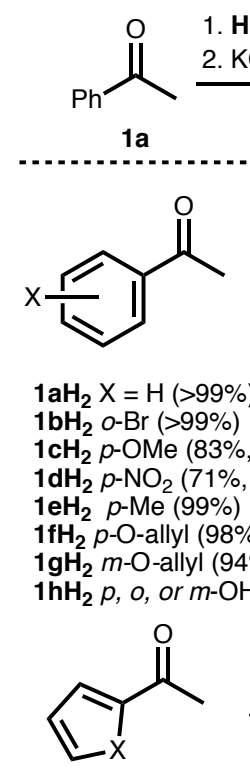

$\mathbf{4 a H} \mathrm{H}_{2} \mathrm{X}=\mathrm{S}(85 \%) \quad \mathbf{4} \mathbf{c H}_{\mathbf{2}}(89 \%)$ $4 \mathrm{bH}_{2} \mathrm{X}=\mathrm{O}(63 \%, 2 \mathrm{~d}, \mathrm{rt})$

The TH of acetophenone (1a) in 2-propanol was found to effectively reach quantitative completion in three hours at $60{ }^{\circ} \mathrm{C}$ with $0.5 \mathrm{~mol} \%$ catalyst loading and $1 \mathrm{~mol} \%$ base (Scheme 2, stoichiometry relative to ketone). The conditions optimized for acetophenone were the same for precatalysts prepared from $\mathbf{H L}^{\mathbf{P h}}$ and $\mathbf{H L}^{\mathrm{Bz}}{ }^{14}$ A series of control experiments were performed for the acetophenone reduction. For instance, $\mathrm{Mn}(\mathrm{CO})_{5} \mathrm{Br}$ is not a catalyst nor does it convert substrate in the presence of any of the amino alcohol ligand precursors (Scheme 1). Additionally, no catalytic activity was observed when base was excluded for trials with $\mathbf{H L}^{\mathrm{Ph}} \mathrm{Mn}(\mathrm{CO})_{3} \mathrm{Br}$.

These conditions tolerated a variety of para and ortho substituted acetophenones (1)-g) with the exception of phenolic acetophenones that were unreactive. Para-nitro required refluxing for three days to achieve an isolated $71 \%$ yield. Benzophenones (2a,b) and aliphatic ketones $(\mathbf{3 a}, \mathbf{b})$ were also hydrogenated effectively. 2-acetyl furan (4a) and 2-acetyl thiophene (4b) were hydrogenated in $63 \%$ and $85 \%$ isolated yields, respectively. 3 -acetyl thiophene (4c), which does not form a chelating alcohol, was converted in $89 \%$ yield. Para-acetyl pyridine (4d) was hydrogenated in $47 \%$ isolated yield after 9 hours, but ortho acetyl pyridine (4e) was not hydrogenated to an appreciable extent ( $9 \%$ conversion by $\left.{ }^{1} \mathrm{H}-\mathrm{NMR}\right)$; presumably the hydrogenated 2-actyl-pyridine poisons the catalyst through a bidentate coordination. Transfer dehydrogenation of the parent 1-phenylethanol $\left(\mathbf{1 a H}_{2}\right)$ in refluxing acetone $\left(56^{\circ} \mathrm{C}\right)$ for 3 hours resulted in only $67 \%$ conversion to acetophenone, suggesting that $\mathrm{TH}$ is favored over the TdH under the conditions studied.

\section{Scheme 3. Transfer Hydrogenation of Chalcones}
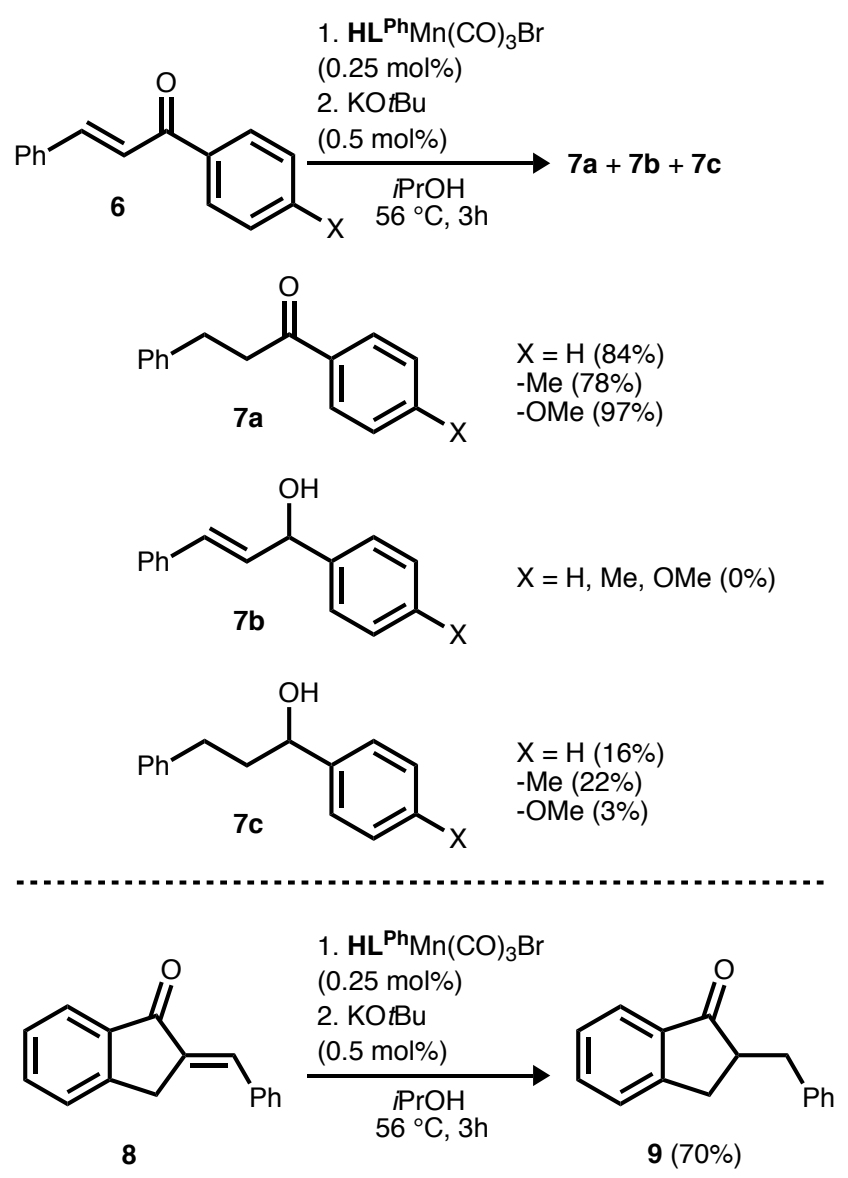

Interestingly, the PN-Mn(I) complexes are chemoselective $1,4 \mathrm{TH}$ catalysts for chalcones to the saturated ketones. Although many conditions are available for 1,4 reductions of chalcones,${ }^{15}$ this report does not require stoichiometric electron transfer reductant and is the first $\mathrm{Mn}$ catalyzed example. Moreover, the reaction conditions here are mild and the product isolation is simple. For instance, trans-chalcone (6) can be converted to 1,3-diphenyl-1-propanone (7a) at $56^{\circ} \mathrm{C}$ in 3 hours using $0.25 \mathrm{~mol} \%$ catalyst loading and $0.5 \mathrm{~mol} \%$ base (Scheme 3). Complete conversion to the saturated alcohol 1,3-diphenyl-1propanol (7c) can be accomplished through overnight heating under the parent conditions with the higher 
catalyst loading ( $0.5 \mathrm{~mol} \%$ catalyst). Furthermore, benzylidene indanone (8) was also hydrogenated to the ketone 9 under the conditions listed above for the chalcone.

\section{Scheme 4. Possible Mechanisms for Chalcone Reduc-} tion

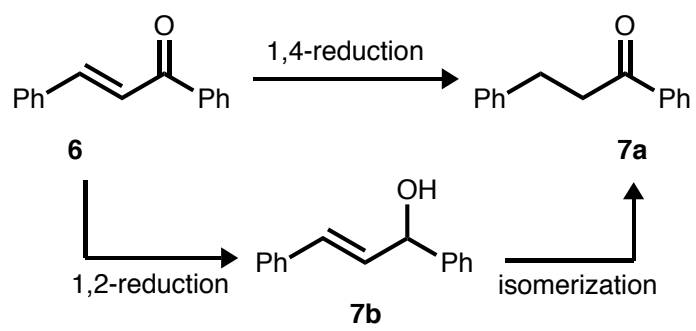

Under no set of conditions did we observe the allylic alcohol $\mathbf{7 b}$ in $\mathrm{TH}$ reactions with chalcone $\mathbf{6}$, indicating that reduction may occur via a 1,4-hydride addition rather than 1,2-reduction followed by isomerization (Scheme 4). We tested this hypothesis by subjecting the 1,3-diphenylprop-2-enol (7b) to the parent conditions in 2-propanol and found no reaction; only unreacted $7 \mathbf{b}$ was recovered. However, $\mathbf{7 b}$ isomerizes to $\mathbf{7 a}$ in toluene in the presence of pre-catalyst $\mathbf{H L}^{\mathbf{P h}} \mathrm{Mn}(\mathrm{CO})_{3} \mathrm{Br}$ and base. Isomerization of $7 \mathbf{b}$ into 7a represents a rare example of a Mn-catalyzed allylic alcohol isomerization reaction. Typically, isomerization of allylic alcohols requires a precious metal catalyst. ${ }^{16}$ Nickel and iron have been utilized, ${ }^{17}$ but no manganese catalyst has been reported. The allylic alcohol isomerization capability of the $\mathbf{H L}^{\mathbf{P h}} \mathrm{Mn}(\mathrm{CO})_{3} \mathrm{Br}$ and base system in toluene was tested for three different allyl alcohols $\mathbf{7 b}, \mathbf{1 0 b}$, and $\mathbf{1 1 b}$ and found quantitative conversion (Scheme 5).

\section{Scheme 5. Allylic Alcohol Isomerization Studies}

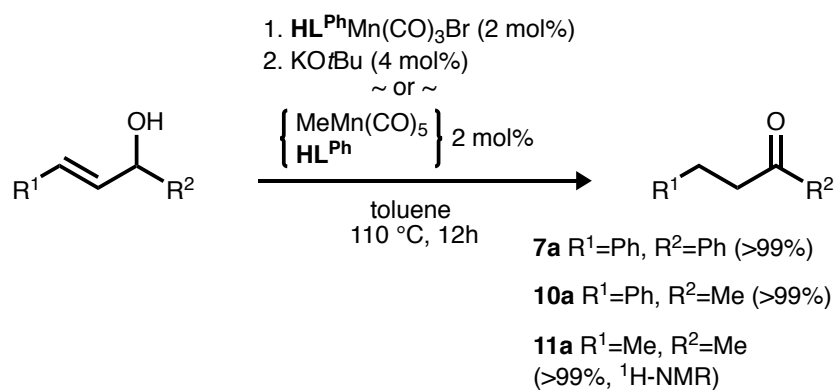

We additionally compared various ligands in the chalcone reduction to see if the phenomenon was general or specific to the PN ligands (Table 1). The oxamide ligand $\mathrm{A}$ did not afford any significant reaction $(<6 \%$ alcohol, no saturated ketone) with the remaining 6 untouched. ${ }^{18}$ 1,2-diaminoethane and its 1,2-diphenyl substituted analog (ligand $\mathbf{B}$ and $\mathbf{C}$, respectively) furnished almost no conversion of $\mathbf{6}^{4,5}$ Pidko's 2-aminomethylprydine (ligand D) precatalyst complex $\mathbf{D M n}(\mathrm{CO})_{3} \mathrm{Br}$ was prepared and used under identical conditions from Scheme 3. In this case, the allyl alcohol $\mathbf{7 b}$ was obtained in $27 \%$ yield, again with the remainder of starting material unreacted. We additionally tested a new PN-Mn complex with ligand $\mathbf{E}^{19}\left(\mathbf{E M n}(\mathrm{CO})_{3} \mathrm{Br}\right)$ and found no conversion of 6. Compared to the parent ligand $\mathbf{H L}^{\mathbf{P h}}$, these catalysts are not chemoselective for the saturated ketone and highlights the viability of ligand design in Mn-based systems that are rapidly emerging in recent years.

Table 1. Effect of ligand in chalcone (6) reduction. ${ }^{(a)}$

\begin{tabular}{|c|c|c|c|c|}
\hline A & $\mathrm{R}=\mathrm{H}(\mathbf{B}), \mathrm{Ph}(\mathbf{C})$ & D & E & $\mathrm{HL}^{\mathrm{Ph}}$ \\
\hline & \multicolumn{4}{|c|}{ yield $^{(\mathrm{b})}(\%)$} \\
\hline Ligand & 6 & $7 a$ & $7 b$ & $7 c$ \\
\hline none $e^{(c)}$ & 100 & 0 & 0 & 0 \\
\hline$H L^{P h}$ & 0 & 84 & 0 & 16 \\
\hline $\mathbf{A}^{(\mathbf{d})}$ & 94 & 0 & 6 & 0 \\
\hline $\mathbf{B}^{(\mathrm{e})}$ & 91 & 0 & 9 & 0 \\
\hline $\mathrm{C}^{(\mathrm{e})}$ & $>99$ & 0 & $<1$ & 0 \\
\hline$D^{(f)}$ & 73 & 0 & 27 & 0 \\
\hline $\mathbf{E}^{(\mathrm{g})}$ & 100 & 0 & 0 & 0 \\
\hline
\end{tabular}

(a) Conditions in Scheme 3 for substrate 6. (b) yields determined from integrations of ${ }^{1} \mathrm{H}-\mathrm{NMR}$ spectrum of residue after solvent removal in vacuo. (c) $\mathrm{Mn}(\mathrm{CO})_{5} \mathrm{Br}$. Catalysts prepared according to literature: (d) ref 18; (e) ref 5; (f) ref 4; (g) This work, see SI.

An earlier report from our group, showed the potential of using methyl manganese pentacarbonyl $\left(\mathrm{CH}_{3} \mathrm{Mn}(\mathrm{CO})_{5}\right)$ forgoing the need to use a base to activate the precatalyst. ${ }^{20}$ Gratifyingly, we found that the ligand $\mathbf{H L}^{\mathrm{Ph}}$ when treated with $\mathrm{CH}_{3} \mathrm{Mn}(\mathrm{CO})_{5}$ generates the same species, among other species, as when the precatalyst is treated with base in toluene ( ${ }^{31} \mathrm{P}$ NMR: $\left.72 \mathrm{ppm}\right)$. When this mixture of species that contained ${ }^{31} \mathrm{P}\left\{{ }^{1} \mathrm{H}\right\} \mathrm{NMR}=72$ ppm was generated in toluene and added to a solution of 1a in 2-propanol and heated, $\mathbf{1 a H}_{2}$ was isolated in $58 \%$ yield. Despite showing only partial reduction for $\mathbf{1 a}$, the $\mathrm{CH}_{3} \mathrm{Mn}(\mathrm{CO})_{5}+\mathbf{H L}^{\mathbf{P h}}$ system generated in situ (substrate + ligand $+\mathrm{CH}_{3} \mathrm{Mn}(\mathrm{CO})_{5}$ ) showed quantitative isomerization of $7 \mathbf{b}$ to $7 \mathbf{a}$ (Scheme 5).

In conclusion, we have demonstrated that beta-amino phosphine supported $\mathrm{Mn}(\mathrm{I})$-carbonyl complexes are excellent catalysts for TH of ketones with good functional group tolerance under mild conditions. Chalcones are selectively reduced to the ketones in short time intervals and appears to be a property of the catalysts derived from beta-amino phosphine ligands and not a variety of other ligands. Additionally, the isomerization of allylic alcohols by the same catalysts was demonstrated and appears to be related to the selectivity of the chalcone reduction. Importantly, these reactions highlight that $\mathrm{Mn}(\mathrm{I})$ is a versatile platform to perform reactions where the ligand 
controls the chemoselectivity. Given its abundance and low-toxicity compared to most other metal ions, this area is expected to see continual growth in unique substrate and chemoselective transformations.

\section{ASSOCIATED CONTENT}

\section{Supporting Information.}

The Supporting Information is appended below.

\section{AUTHOR INFORMATION}

\section{Corresponding Author}

DCLacy@Buffalo.edu

1. Wang, D.; Astruc, D. The golden age of transfer hydrogenation. Chem. Rev. 2015, 115, 6621-6686.

2. Perez, M.; Elangovan, S.; Spannenberg, A.; Junge, K.; Beller, M. Molecularly defined manganese pincer complexes for selective transfer hydrogenation of ketones. ChemSusChem. 2017, 10, 83-86.

3. Zirakzadeh, A.; de Aguiar, S. R. M. M.; Stöger, B.; Widhalm, M.; Kirchner, K. Enantioselective transfer hydrogenation of ketones catalyzed by a manganese complex containing an unsummetrical chiral PNP' tridentate ligand. ChemCatChem. 2017, 9, 1744-1748.

4. Bruneau-Voisine, A.; Wang, D.; Dorcet, V.; Roisnel, T.; Darcel, C.; Sortais, J-B. Transfer hydrogenation of carbonyl derivatives catalyzed by an inexpensive phosphine-free manganese precatalyst. Org. Lett., 2017, 19, 3656-3659.

5. Wang, D.; Bruneau-Voisine, A.; Sortais, J-B. Practical (asymmetric) transfer hydrogenation of ketones catalyzed by manganese with (chiral) diamines ligands. Catal. Commun. 2018, 105, 31-36.

6. M-F., O.; Werlé, C.; Frincio, G.; Leitner, W. Aminotriazole $\mathrm{Mn}(\mathrm{I})$ complexes as effective catalysts for transfer hydrogenation. ChemCatChem. 2018, 10, 4514-4518.

7. Ganguli, K.; Shee, S.; Panja, D.; Kundu, S. Dalton Trans. 2019, 48, 7358-7366.

8. Zell, T.; Langer, R. From ruthenium to iron and manganese-A mechanistic view on challenges and design principles of basemetal hydrogenation catalysts. ChemCatChem. 2018, 10, 1930-1940..

9. van Putten, R.; Uslamin, E. A.; Garbe, M.; Liu, C.; Gonzalezde-Castro, A.; Lutz, M.; Junge, K.; Hensen, E. J. M.; Beller, M.; Lefort, L.; Pidko, Evgeny A. Non-pincer-type manganese complexes as efficient catalysts for the hydrogenation of esters. Angew. Chem. Int. Ed. 2017, 56, 7531-7534.

10. Dubey, A.; Rahaman, S. M. W.; Fayzullin, R. R.; Khusnutdinova, J. R. Transfer hydrogenation of carbonyl groups, imines and $N$-heterocycles catalyzed by simple, bipyridine-based $\mathrm{Mn}(\mathrm{I}) \quad$ complexes. ChemCatChem DOI: 10.1002/cctc.201900358.

11. McKennon, M. J.; Meyers, A. I.; Drauz, K.; Schwarm, M. A convenient reduction of amino acids and their derivatives. $J$. Org. Chem. 1993, 58 (13), 3568-3571.

12. Ghosh, A.; Brezden, A. M.; Mustafa, T. A.; Sullivan, S. Z.; Padmanabhan, S.; Munshi, P. An economically viable process for the synthesis of a chiral oxazolidinone ((S))-4-benzyl-2oxazolidinone) from amino acid. Part. Sci. Technol. 2011, 29 (5), 466-474

13. Ito, M.; Osaku, A.; Kobayashi, C.; Shiibashi, A.; Ikariya, T. A Convenient Method for the synthesis of protic 2-(tertiary

\section{ACKNOWLEDGMENT}

Financial support was provided by the University at Buffalo (UB) Research Foundation, the ACS Petroleum Research Fund (ACS-PRF-57861-DN13), and the National Science Foundation (1847933). This work used the UB Chemistry Instrument Center facilities; the mass spectrometer used for this work was supported by award S10RR029517 from the National Center for Research Resources; Kevin Zemaitis is acknowledged for HRMS analysis of $\mathbf{E M n}(\mathrm{CO})_{3} \mathrm{Br}$. Paul M. Fanara is thanked for the synthesis of $\mathbf{E}$.

\section{REFERENCES}

phosphino)-1-amines and their $\mathrm{Cp} * \mathrm{RuCl}$ complexes. Organometallics 2009, 28 (2), 390-393.

14. The enantiomeric excess from $\mathrm{TH}$ in this study did not exceed $11 \%$ (highest from phenylglycine derived PN ligand).

15. Prasanna, R.; Guha, S.; Sekar, G. Proton-coupled electron transfer: Transition-metal-free reduction of chalcones and alkynes using xanthate/formic acid. Org. Lett. 2019, 21, 26502653.

16. Examples of allylic alcohol isomerization using precious metal catalysts: (a) van der Drift, R. C.; Bouwman, E.; Drent, E. Homogeneously catalyzed isomerization of allylic alcohols to carbonyl compounds. J. Organomet. Chem. 2002, 650, 124. (b) Li, H.; Mazet, C. Catalyst-directed diastereoselective isomerization of allylic alcohols for the stereoselective construction of C(20) in steroid side chains: scope and topological diversification. J. Am. Chem. Soc. 2015, 137 (33), 1072010727. (c) Horvath, H.; Katho, A.; Udvardy, A.; Papp, G.; Szikszai, D.; Joo, F. New water-soluble iridium(I)-N-heterocyclic carbene-tertiary phosphine mixed-ligand complexes as catalysts of hydrogenation and redox isomerization. Organometallics 2014, 33 (22), 6330-6340. (d) Lin, L.; Romano, C.; Mazet, C. Palladium-catalyzed long-range deconjugative isomerization of highly substituted $\alpha, \beta$-unsaturated carbonyl compounds. J. Am. Chem. Soc. 2016, 138 (32), 10344-10350. (e) Voronova, K.; Purgel, M.; Udvardy, A.; Benyei, A. C.; Katho, A.; Joo, F. Hydrogenation and redox isomerization of allylic alcohols catalyzed by a new water-soluble Pd-tetrahydrosalen complex. Organometallics 2013, 32 (15), 43914401. (f) Bergens, S. H.; Bosnich, B. Homogeneous catalysis. Catalytic production of enols. J. Am. Chem. Soc. 1991, 113 (3), 958-967. (g) Kress, S.; Johnson, T.; Weisshar, F.; Lautens, M. Synthetic and mechanistic studies on the rhodium-catalyzed redox isomerization of cyclohexa-2,5-dienols. ACS Catal. 2016, 6 (2), 747-750. (h) Kulawiec, R. J.; Trost, B. M. A chemoselective internal redox of allyl alcohols to saturated aldehydes or ketones. Tet. Lett. 1991, 32 (26), 3039-3042. (i) Ito, M.; Kitahara, S.; Ikariya, T. CpRu(PN) complex-catalyzed isomerization of allylic alcohols and its application to the asymmetric synthesis of muscone. J. Am. Chem. Soc. 2005, 127 (17), 6172-6173.

17. (a) Lochow, C. F.; Miller, R. G. Nickel-promoted isomerizations of alkenes bearing polar functional groups. J. Org. Chem. 1976, 41 (18), 3020-3022. (b) Xia, T.; Wei, Z.; Spiegelberg, B.; Jiao, H.; Hinze, S.; de Vries, J. G. Isomerization of allylic alcohols to ketones by well-defined iron PNP pincer catalysts. Chem. Eur. J. 2017, 24 (16), 4043-4049. 
18. Schneekönig, J.; Junge, K.; Beller, M. Manganese catalyzed asymmetric transfer hydrogenation of ketones. Synlett 2019, 30 (4), 503-507.

19. Gerald, E. P.; Andrew, F. I.; Stuart, Y. B. Heterocycle-containing phosphines \& their use as ligands in palladium

catalysed coupling reactions. Brit. UK Pat. Appl. GB2378182 (A), February 5, 2003.

20. Kadassery, K. J.; Lacy, D. C. Pentacarbonylmethylmanganese(I) as a synthon for $\mathrm{Mn}(\mathrm{I})$ pincer catalysts. Dalton Trans. 2019, 48, 4467-4470. 
TOC Graphic 


\section{TOC graphic:}

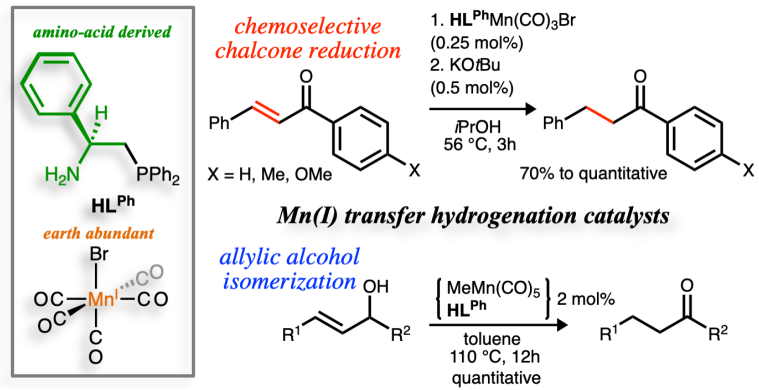

TOC synopsis: Beta-amino phosphines derived from amino-acids are excellent supporting ligands for $\mathrm{Mn}(\mathrm{I})$ transfer hydrogenation catalysts. Namely, a variety of ketones and chalcones are efficiently reduced under mild conditions (2-propanol, $3 \mathrm{~h}, 60$ $\left.{ }^{\circ} \mathrm{C}\right)$. Moreover, chalcones are selectively reduced to the saturated ketone in 2-propanol and allylic alcohols are quantitatively converted into the same product in toluene. 
Beta-Amino Phosphine Mn Catalysts for 1,4-Transfer Hydrogenation of Chalcones and Allylic Alcohol Isomerization

Vipulan Vigneswaran and David C. Lacy*

Department of Chemistry, University at Buffalo, State University of New York, Amherst, New York 1426o, United States.

E-mail: DCLacy@buffalo.edu

\section{Contents}

General considerations

Ligand Synthesis and Characterization

Complex Synthesis and Characterization

Substrate Scope

References
Page

S2

S2

S3-S6

S7-S21

S21 


\section{General Considerations}

Chemicals were obtained from commercial vendors unless noted. All manipulations of oxygen sensitive compounds were performed under an argon atmosphere with standard Schlenk techniques or under nitrogen in a VAC Atmosphere Genesis Glovebox. Anhydrous toluene and diethyl ether were purified using a Pure Process Technology solvent purification system and were stored over $3 \AA$ molecular sieves before use. Degassed protic solvents were degassed via sparging with argon that was passed over Drierite.

${ }^{1} \mathrm{H}$ NMR spectra were recorded on a Varian Mercury-300 or Varian Inova-400 MHz spectrometer referenced to residual solvent proton signals. ${ }^{31} \mathrm{P}$ NMR spectra were recorded on a Varian Mercury-300 $\mathrm{MHz}$ spectrometer referenced to an external $\mathrm{H}_{3} \mathrm{PO}_{4}(85 \%)$ standard. Transmission ATR-FTIR spectra were collected using a Bruker Alpha IR spectrometer with ALPHA-P Platinum ATR module (diamond crystal) under an argon atmosphere inside of a VAC Atmospheres Omni Glovebox. Ketones were purchased from commercial vendors and their respective chalcones were synthesized from a literature procedure. ${ }^{1}$ Allyl alcohols were synthesized from a literature procedure from their respective enones. ${ }^{2}$ Bishydroxyethyloxamide ligand and 2-((di-tert-butylphosphaneyl)methyl)pyridine were synthesized following literature procedures.3,4 2-aminomethylpyridine, ethylene diamine and 1,2-diphenylethylenediamine were obtained from commercial sources.

\section{Ligand Synthesis}

(S)-2-(diphenylphosphanyl)-1-phenylethan-1-amine (HL $\left.{ }^{\mathrm{Ph}}\right)$. The ligand was synthesized following a modified literature report.5 In a glovebox, a $100 \mathrm{~mL}$ Schlenk flask, equipped with a stirbar, was charged with $20 \mathrm{~mL}$ of dry, degassed toluene. (S)-4-phenyl-2-oxazolidinone (326 mg, $2.0 \mathrm{mmol}, 1$ eq.) was added and allowed to stir at room temperature for 15 minutes to form a well dispersed suspension. To this suspension, diphenylphosphine was added in one portion by Pasteur pipette (633 mg, $3.4 \mathrm{mmol}$, 1.7 eq.). This mixture was allowed to stir for a further 30 minutes. The flask was subsequently sealed with a rubber septum and Teflon stopper and brought out of the glovebox, brought under positive argon flow and then placed in a mineral oil bath to stir at room temperature. Trifluoromethanesulfonic acid ( $476 \mu \mathrm{L}, 5.4 \mathrm{mmol}$. 2.7 eq.) was added via glass syringe in one portion. It was noted that thin, wispy, fumes appear within the flask at this time. Once the fumes had subsided, the rubber septum was removed, and a cold finger was equipped to the flask. The cold finger was connected to a temperature-controlled circulator and maintained at $15{ }^{\circ} \mathrm{C}$. The mixture was then brought to reflux for a period of 24 hours. As the reaction reached reflux temperature, the mixture was noted to be more homogeneous.

Upon conclusion of heating, the mixture was brought back to room temperature and the cold finger was removed and replaced with a rubber septum under positive argon flow. To this mixture, degassed, saturated $\mathrm{K}_{2} \mathrm{CO}_{3}$ solution (10 $\mathrm{mL}$ ) was added via cannula. The reaction was allowed to quench for a period of 30 minutes and was then extracted with the addition of degassed diethyl ether $(20 \mathrm{~mL})$, three times. The diethyl ether extractions were cannula transferred to another flask with anhydrous sodium sulfate, then transferred into a Schlenk flask and evacuated to yield an oil or glassy solid. The oil was dissolved in petroleum ether $(10 \mathrm{~mL})$ and stirred at room temperature. The oil/petroleum ether mixture was transferred into a glass scintillation vial and placed in a freezer at $-35{ }^{\circ} \mathrm{C}$ overnight. The ligand precipitated $(523 \mathrm{mg}$, $85 \%$ yield) and isolated. The spectral features of the product were in agreement with literature characterization values. ${ }^{1} \mathrm{H}$ NMR $(300 \mathrm{MHz}$ ) $\delta 7.73-6.95(\mathrm{~m}, 14 \mathrm{H}), 4.00$ (ddd, $J=9.3,7.4,4.8 \mathrm{~Hz}, 1 \mathrm{H})$, 2.53 (ddd, $J=13.6,4.8,2.3 \mathrm{~Hz}, 1 \mathrm{H}$ ), 2.41 (ddd, $J=13.7,9.2,2.2 \mathrm{~Hz}, 1 \mathrm{H}$ ). Characterization Figure S1-S2 


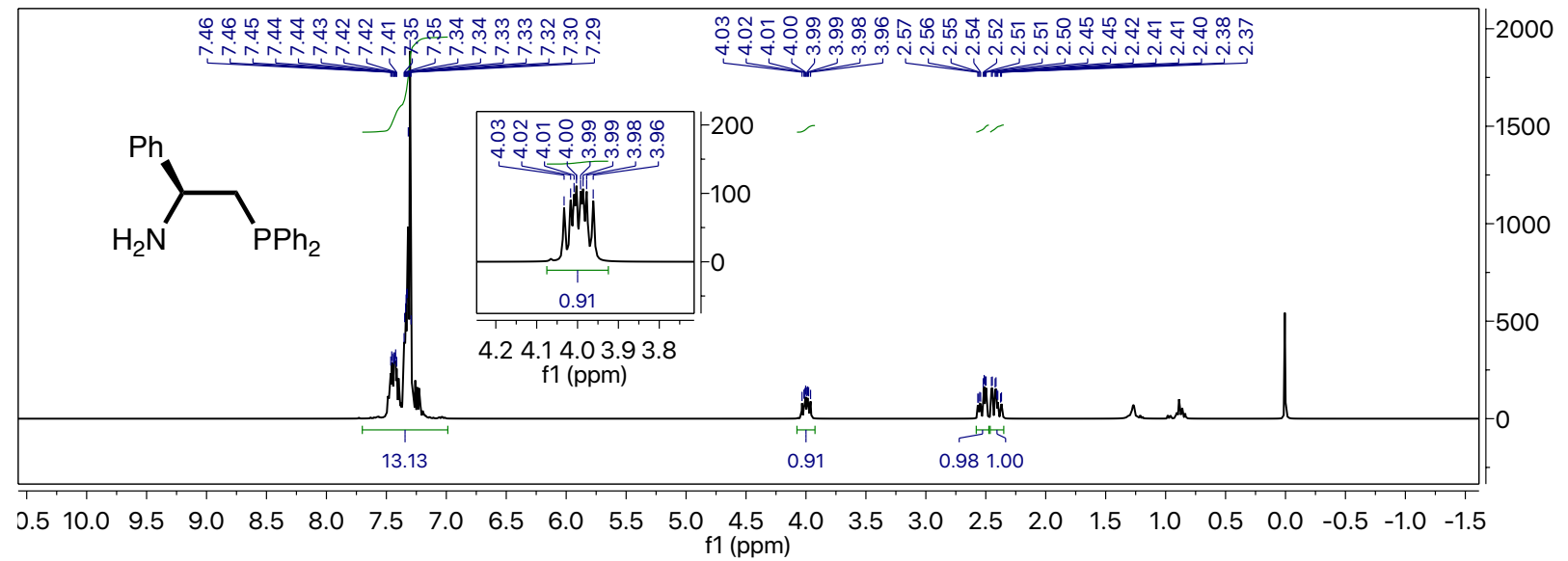

Figure S1. ${ }^{1} \mathrm{H}$ NMR spectrum of $\mathbf{H L}^{\mathbf{P h}}$ in $\mathrm{CDCl}_{3}\left({ }^{*}\right)$.

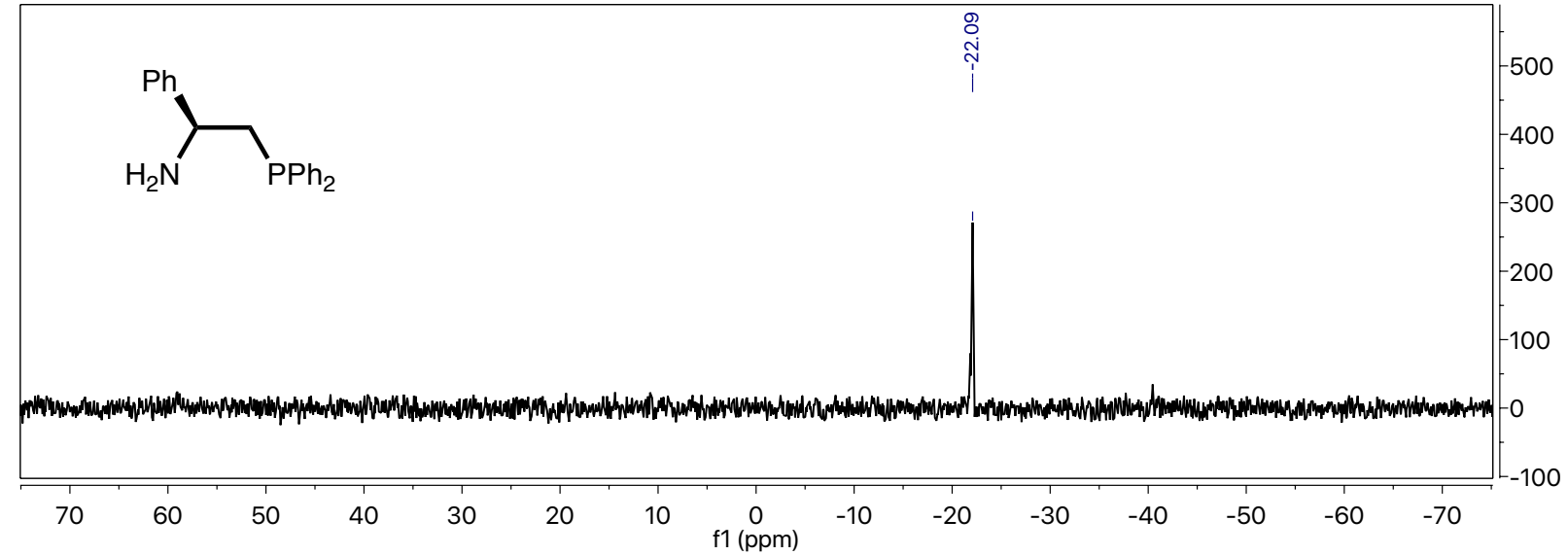

Figure S2. ${ }^{11} \mathrm{P}$ NMR Spectrum of ligand in $\mathrm{CDCl}_{3}$.

\section{Complex Synthesis}

$\mathrm{HL}^{\mathrm{Ph}} \mathrm{Mn}(\mathrm{I}) \mathrm{CO}_{3} \mathbf{B r}$. The procedure is modified from a synthesis of $\mathbf{H L}^{\mathbf{H}} \mathrm{Mn}(\mathrm{CO})_{3} \mathrm{Br} .{ }^{6} \mathrm{In}$ a glove box, a $\mathbf{2 5}^{-}$ $\mathrm{mL}$ thick-walled glass Schlenk bomb, equipped with a stir bar, was charged with degassed, anhydrous toluene $(4 \mathrm{~mL})$ and the ligand $(198 \mathrm{mg}, 0.65 \mathrm{mmol})$. The mixture was stirred at room temperature for 5 minutes. Bromopentacarbonylmanganese(I) $(178 \mathrm{mg}, 0.65 \mathrm{mmol})$ was then added in one portion. The reaction bomb was then sealed and stirred at room temperature for 5 minutes. Carbon monoxide liberation was observed as a stream of microbubbles formed from the solution. The mixture is then removed from the glovebox and heated at $100^{\circ} \mathrm{C}$ for 12 hours. The mixture changes color from orange to a golden yelloworange color over this time. Upon conclusion of heating, the reaction bomb is brought back into the glovebox and the mixture is transferred to a tared scintillation vial. The solvent was removed in vacuo and the resulting residue was dissolved in a minimal amount of THF $(\sim 2.5 \mathrm{~mL})$. The concentrated THF solution was then layered under petroleum ether that yielded yellow-orange crystals (283 mg, 83 \%). ${ }^{1} \mathrm{H}$ NMR (300 $\left.\mathrm{MHz}, \mathrm{CD}_{2} \mathrm{Cl}_{2}\right) \delta 7.84\left(t, \mathrm{~J}=6 \mathrm{~Hz}, 2 \mathrm{H}, \mathrm{PC}_{6} \mathrm{H}_{6}-m-H\right), 7.69\left(t, \mathrm{~J}=6 \mathrm{~Hz}, 2 \mathrm{H}, \mathrm{PC}_{6} \mathrm{H}_{6}-m-H\right) 7.52-7.41(m, 11 \mathrm{H}$, $\mathrm{Ar}-H, \mathrm{PC}_{6} \mathrm{H}_{6}-\mathrm{O}-H$, and $\left.\mathrm{PC}_{6} \mathrm{H}_{6}-p-H\right), 3.99(s, 1 \mathrm{H}, \mathrm{N}-H \mathrm{H}), 3.77(s, 1 \mathrm{H}, \mathrm{N}-\mathrm{H} H), 3.19\left(t, \mathrm{~J}=14 \mathrm{~Hz}, 2 \mathrm{H}, \mathrm{C}-H_{2}\right)$, $2.76(t, \mathrm{~J}=14 \mathrm{~Hz}, 1 \mathrm{H}, \mathrm{C}-H) .{ }^{31} \mathrm{P}\left\{{ }^{1} \mathrm{H}\right\}$ NMR $\left(121 \mathrm{MHz}, \mathrm{CDCl}_{3}\right): 53.8 \mathrm{ppm}$. FTIR-ATR: 2017, 1935, $1901 \mathrm{~cm}^{-1}$. Anal. Calcd. for $\mathrm{C}_{23} \mathrm{H}_{20} \mathrm{NO}_{3} \mathrm{MnBr}$ : C, 52.70\%; H, 3.85\%; N, 2.67\%. Anal. Found for $\mathrm{C}_{23} \mathrm{H}_{20} \mathrm{NO}_{3} \mathrm{MnBr}$ : C, 52.67\%; H, 4.01\%; N, 2.63\%. Characterization Figures S3-S5 


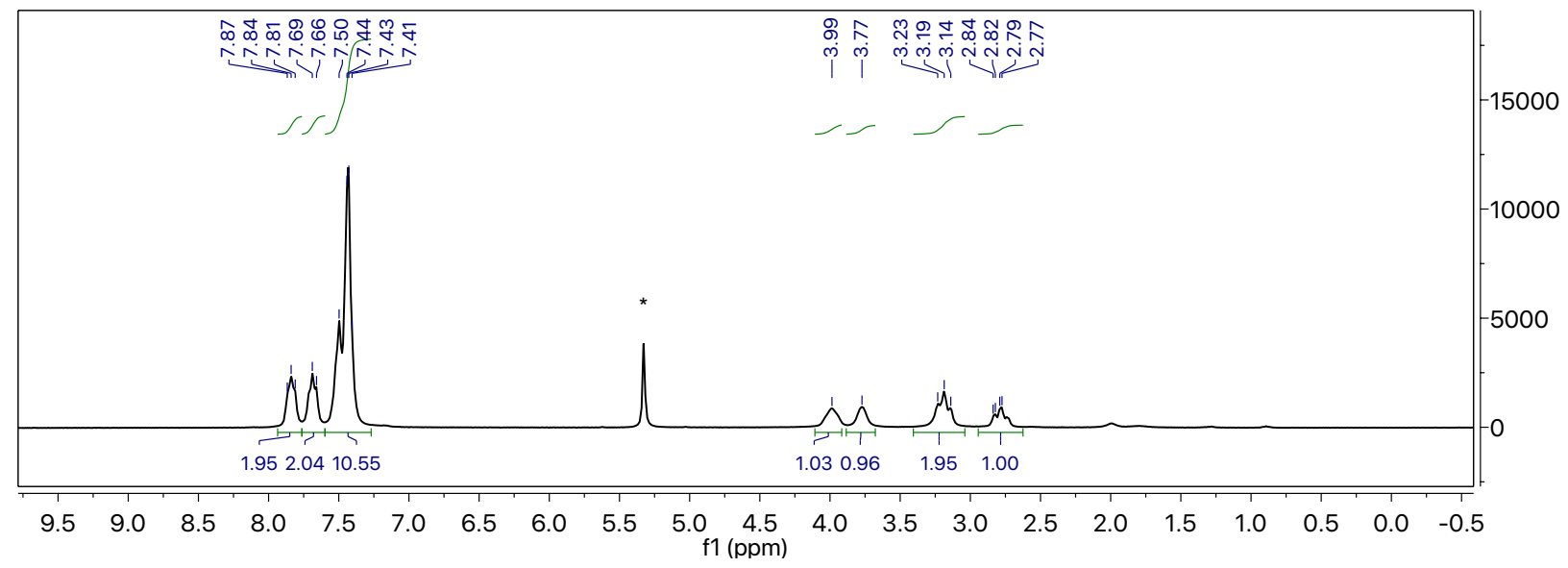

Figure S3. ${ }^{1} \mathrm{H}$ NMR spectrum of $\mathbf{H L}^{\mathrm{Ph}} \mathrm{Mn}(\mathrm{I}) \mathrm{CO}_{3} \mathrm{Br}$ in $\left.\mathrm{CD}_{2} \mathrm{Cl}_{2}{ }^{*}\right)$.

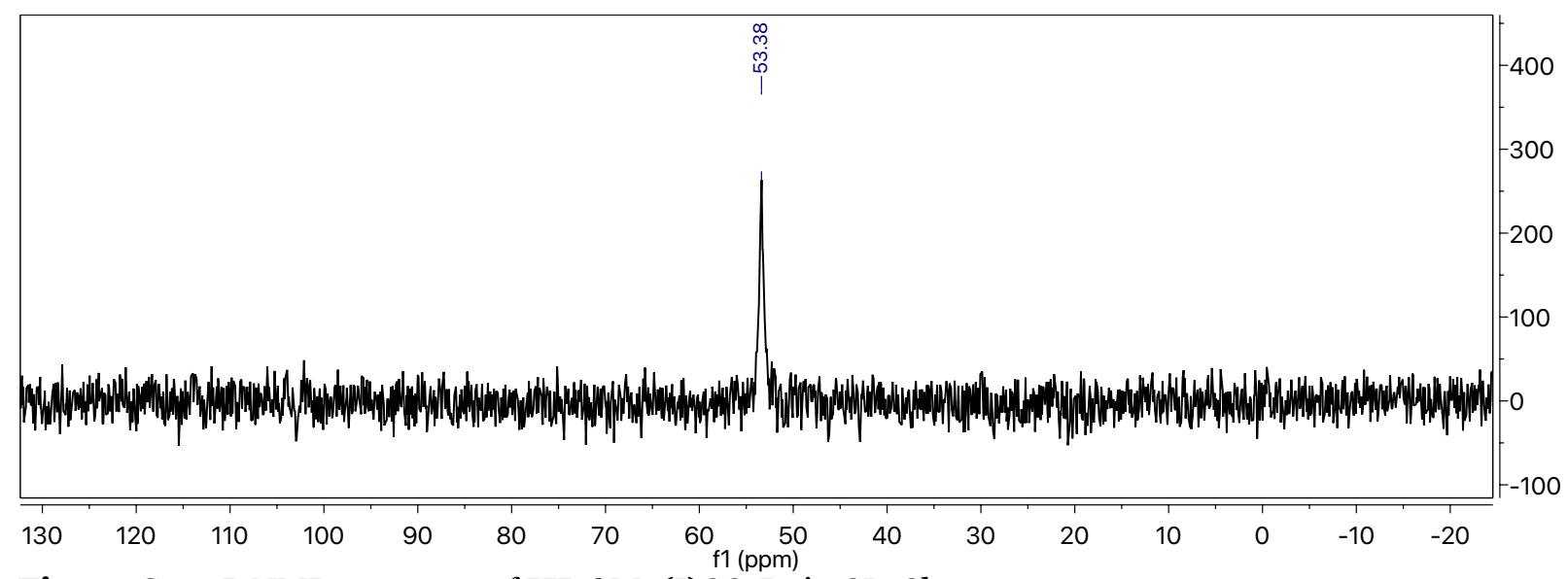

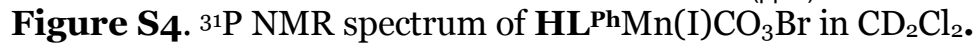

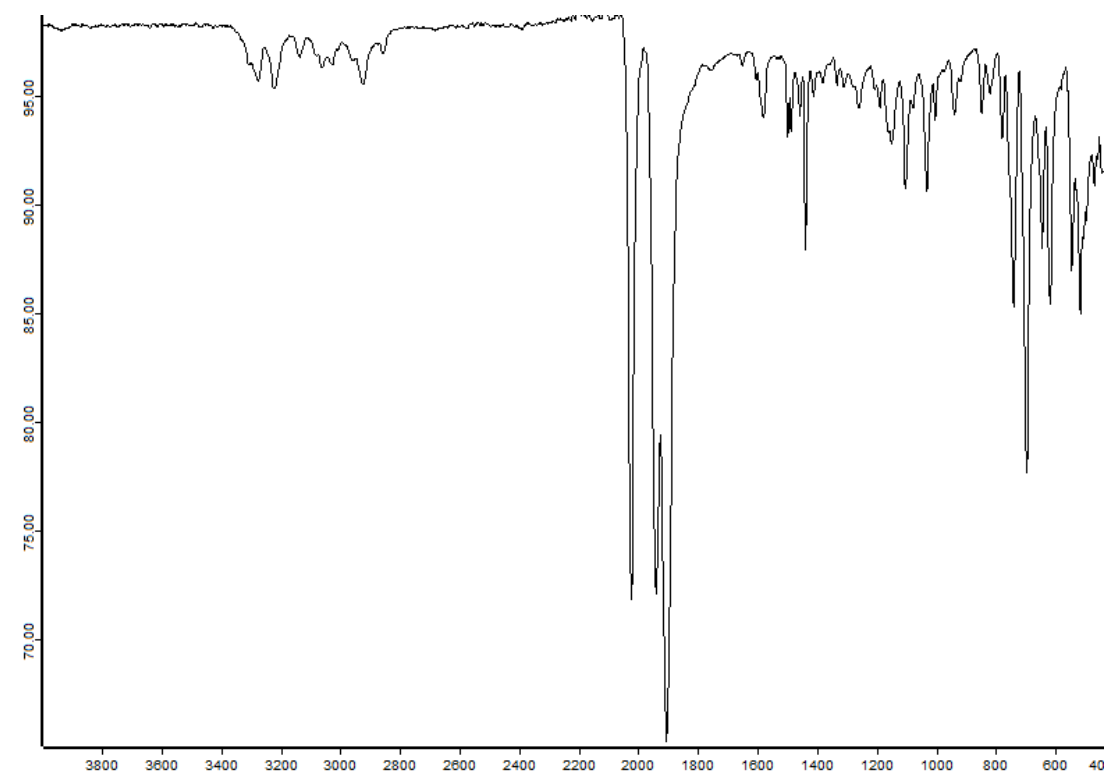

Figure S5. FTIR-ATR spectrum of $\mathbf{H L}^{\mathrm{Ph} M n(\mathrm{I}) \mathrm{CO}_{3} \mathrm{Br}}$ 
$\mathbf{L}^{\mathbf{P h}} \mathbf{M n}(\mathbf{I}) \mathbf{C O}_{3}$. Solutions containing the complex tentatively assigned as $\mathbf{L}^{\mathbf{P h}} \mathbf{M n}(\mathrm{I}) \mathrm{CO}_{3}$ was generated by one of two methods:

(a) From HLPhMn(I)CO $\mathrm{CO}_{3} \mathrm{Br}$ : In a nitrogen filled glovebox, a stirbar equipped scintillation vial was loaded with

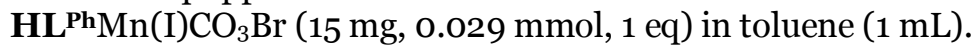
To this pale yellow solution potassium tert-butoxide $(3 \mathrm{mg}$, $0.03,1$ eq) was added in one portion and allowed to stir for 30 minutes, which induced a color change to amber. A $450 \mu \mathrm{L}$ aliquot of the resulting homogeneous solution was transferred to a J-Young tube. ${ }^{31} \mathrm{P}\left\{{ }^{1} \mathrm{H}\right\}$ NMR spectra showed mostly unreacted precatalyst $\mathbf{H L}^{\mathbf{P h}} \mathrm{Mn}(\mathrm{I}) \mathrm{CO}_{3} \mathrm{Br}$. The tube was heated over night at $100{ }^{\circ} \mathrm{C}$ giving rise to a $\sim 1: 1$ mixture of $\mathrm{HL}^{\mathrm{Ph}} \mathrm{Mn}(\mathrm{I}) \mathrm{CO}_{3} \mathrm{Br}$ and a new species $\left({ }^{31} \mathrm{P}\left\{{ }^{1} \mathrm{H}\right\} \mathrm{NMR}(121 \mathrm{MHz}\right.$, toluene) $72.8 \mathrm{ppm}$ ) tentatively assigned as $\mathbf{L}^{\mathbf{P h}} \mathbf{M n}(\mathbf{I}) \mathbf{C O}_{3}$ (Figure S6a).

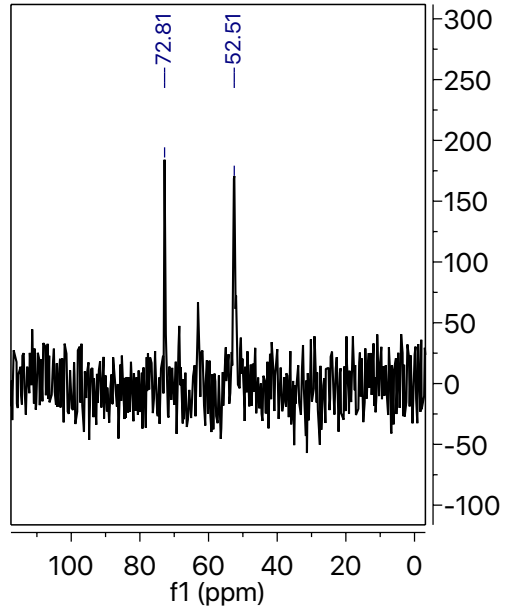

Figure S6a. ${ }^{3} \mathrm{P}\{1 \mathrm{H}\} \quad \mathrm{NMR}$ spectrum from overnight heating of $\mathbf{H L}^{\mathrm{Ph}} \mathrm{Mn}(\mathrm{I}) \mathrm{CO}_{3} \mathrm{Br}$ and $\mathrm{KOtBu}$ in toluene.

(b) From $\mathrm{HL}^{\mathrm{Ph}}$ and $\mathrm{MeMn}(\mathrm{CO})_{5}$ : In a nitrogen filled glovebox, toluene stock solutions of methyl manganese pentacarbonyl (60.5 $\mathrm{mM}$ ) and $\mathbf{H L}^{\mathbf{P h}}$ were prepared (60.5 $\mathrm{mM}$ ). To a J-Young NMR tube, $275 \mu \mathrm{L}$ of both stock solutions were added and slowly heated to $100^{\circ} \mathrm{C}$. The solution was initially clear and colorless and over time became pale yellow and later amber. The mixture was heated over night at the same temperature. The ${ }^{31} \mathrm{P}\{1 \mathrm{H}\}$ NMR spectrum contains several peaks (Figure S6b): 79.8-78.5 (br), 74.3-72.3 (br), 65.4 ppm.

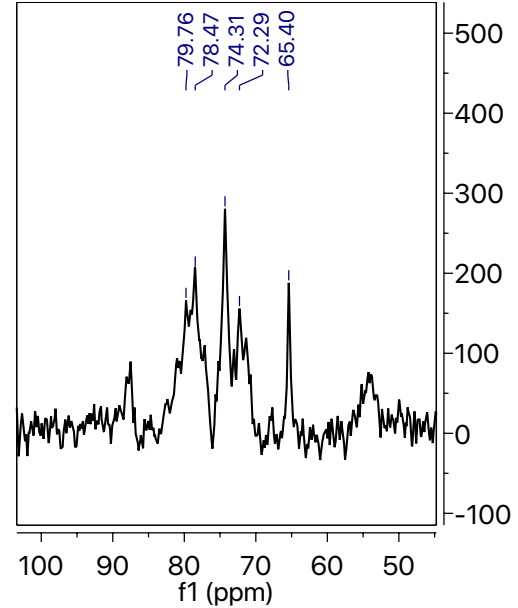

Figure S6b. ${ }^{3} \mathrm{P}\left\{{ }^{1} \mathrm{H}\right\} \quad \mathrm{NMR}$ spectrum from the mixture of HL $^{\text {Ph }}$ and $\mathrm{MeMn}(\mathrm{CO})_{5}$ in toluene $\left(18 \mathrm{~h}, 100^{\circ} \mathrm{C}\right)$. 
PicPtBuMn(I)CO $\mathbf{C O}_{3} \mathbf{B r}$. This complex was generated by the same procedure as $\mathbf{H L}^{\mathbf{P h}} \mathbf{M n}(\mathbf{I}) \mathbf{C O}_{3} \mathbf{B r}$, except using 2-((di-tert-butylphosphaneyl)methyl)pyridine ( $86 \mathrm{mg}, 0.36 \mathrm{mmol}, 1 \mathrm{eq})$ as the ligand. Crystals were grown from layering the crude reaction residue in THF under petroleum ether (23 $\mathrm{mg}, 15 \%$ crystalline yield). ${ }^{1} \mathrm{H}$ NMR (300 MHz, $\left.\mathrm{CD}_{2} \mathrm{Cl}_{2}\right) \delta 9.06\left(\mathrm{~d}, J=5.7 \mathrm{~Hz}, 1 \mathrm{H}, \mathrm{Ar}-H_{A}\right), 7.73\left(\mathrm{t}, J=7.6 \mathrm{~Hz}, 1 \mathrm{H}, \mathrm{Ar}-H_{C}\right), 7.44$ $\left(\mathrm{d}, J=7.8 \mathrm{~Hz}, 1 \mathrm{H}, \mathrm{Ar}-H_{D}\right), 7.22\left(\mathrm{t}, J=6.7 \mathrm{~Hz}, 1 \mathrm{H}, \mathrm{Ar}-H_{B}\right), 3.87(\mathrm{dd}, J=16.5,8.1 \mathrm{~Hz}, 1 \mathrm{H}, \mathrm{Ar}-\mathrm{CH} H), 3.47$ (dd, $J=16.4,9.0 \mathrm{~Hz}, 1 \mathrm{H}, \mathrm{Ar}-\mathrm{CHH}), 1.44\left(\mathrm{~d}, J=12.8 \mathrm{~Hz}, 9 \mathrm{H}, \mathrm{P}-\mathrm{C}-\left(\mathrm{CH}_{3}\right)\right), 1.36\left(\mathrm{~d}, J=12.5 \mathrm{~Hz}, 9 \mathrm{H}, \mathrm{P}-\mathrm{C}-\left(\mathrm{CH}_{3}\right)\right)$. ${ }^{31} \mathrm{P}\left\{{ }^{1} \mathrm{H}\right\}$ NMR (121 MHz, $\mathrm{CDCl}_{3}$ ): $88.2 \mathrm{ppm}$. HRMS (FT-ICR-MS): [M-Br] = 376.0857571. Calculated: 376.08743. Characterization Figure S7-S8

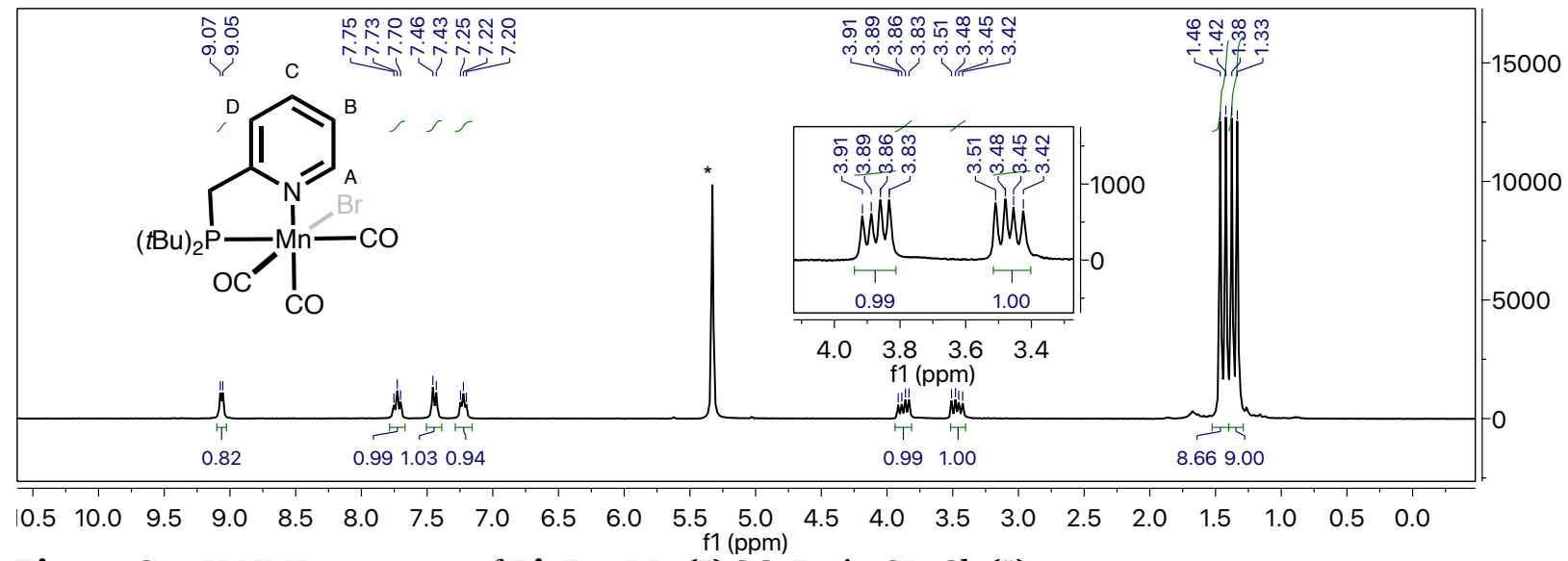

Figure S7. ${ }^{1} \mathrm{H}$ NMR spectrum of PicPtBu $\mathbf{M n}(\mathbf{I}) \mathbf{C O}_{3} \mathbf{B r}$ in $\mathrm{CD}_{2} \mathrm{Cl}_{2}\left({ }^{*}\right)$.

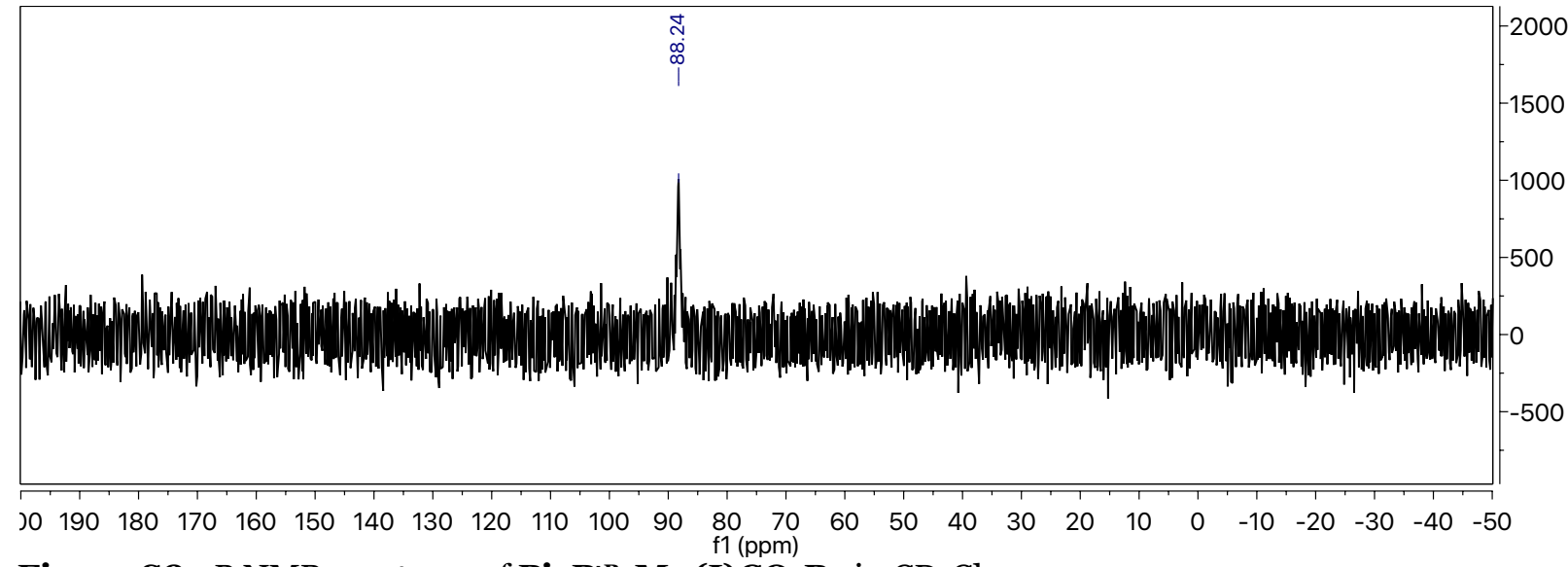

Figure S8 ${ }^{31} \mathrm{P}$ NMR spectrum of PicPtBu$M n(I) C_{3} \mathbf{B r}$ in $\mathrm{CD}_{2} \mathrm{Cl}_{2}$. 


\section{Substrate Scope}

\section{General Procedure}

Ketone transfer hydrogenation: An argon filled Schlenk flask or tube equipped with a small stir bar was charged with the ketone $(0.191 \mathrm{mmol})$ followed by $0.5 \mathrm{~mL}$ of degassed 2-propanol and allowed to stir for 2 minutes. The appropriate amount stock solution containing $\mathbf{H L}^{\mathbf{P h}} \mathrm{MnCO}_{3} \mathrm{Br}(0.5 \mathrm{~mol} \%, 0.955 \mathrm{mM})$ was added to the degassed 2-propanol and allowed to stir for 10 minutes. The appropriate amount of a stock solution of $\mathrm{KO}^{t} \mathrm{Bu}$ in 2-propanol $(1 \mathrm{~mol} \%, 1.91 \mathrm{mM})$ was added thereafter. The mixture was then heated at $60{ }^{\circ} \mathrm{C}$ for a period of 3 hours. The mixture was then passed through a short 2-inch silica plug (pipette) and then 2-propanol was removed in vacuo to obtain pure product. The isolated \% yields and ${ }^{1} \mathrm{H}$ - and ${ }^{13} \mathrm{C}-\mathrm{NMR}$ spectra of isolated compounds are provided below. Incomplete conversions or crude materials were further purified by column chromatography, using EtOAc:Hex (5:95) unless otherwise mentioned.

Chalcones and $\alpha, \beta$-unsaturated compound transfer hydrogenation: The same procedure as above was used except the substrate amount was doubled (same concentration).

Allylic alcohol isomerization conditions: Under an inert atmosphere of nitrogen, in a glovebox, a thickwalled glass Schlenk bomb equipped with a stirbar was charged with toluene (4 mL) and $\mathbf{H L}^{\mathbf{P h}} \mathrm{MnCO}_{3} \mathrm{Br}$ (5.5 mg, $0.010 \mathrm{mmol}, 1$ eq., 2 mol\% relative to substrate). The mixture was stirred until no more solids were observed. To this mixture, the allyl alcohol $(0.5 \mathrm{mmol})$ was added in one portion and stirred until homogeneous. Finally, $\mathrm{KO}^{\mathrm{t}} \mathrm{Bu}(2.2 \mathrm{mg}$, $0.020 \mathrm{mmol}, 2$ eq., $4 \mathrm{~mol} \%$ relative to substrate) was added to the reaction mixture. The vessel was then sealed and brought outside of the glovebox and heated to $110{ }^{\circ} \mathrm{C}$ for a period of 12 hours. The mixture was then allowed to return to room temperature and passed over a 1-inch celite plug (pipette). The toluene is thereafter removed in vacuo to obtain pure product as a solid or oil. For the isomerization of 3 -penten-2-ol, the above was carried out in toluene- $d_{8}$ and the pure product was characterized directly with NMR spectroscopy after passing the reaction mixture through the celite plug.

Characterization of products: description, (\% yield). Characterization; ${ }^{1} \mathrm{H}$ NMR spectrum (top), ${ }^{13 \mathrm{C}} \mathrm{NMR}$ spectrum (bottom)

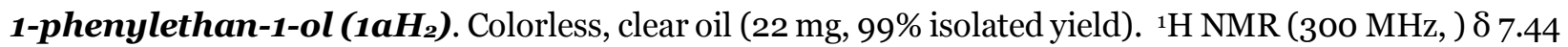
$-7.23(\mathrm{~m}, 5 \mathrm{H}), 4.90$ (qd, $J=6.4,3.4 \mathrm{~Hz}, 1 \mathrm{H}), 1.92(\mathrm{~s}, 1 \mathrm{H}), 1.5 \mathrm{O}(\mathrm{d}, J=6.5 \mathrm{~Hz}, 3 \mathrm{H}) .{ }^{13 \mathrm{C}} \mathrm{NMR}(75 \mathrm{MHz}$, $\left.\mathrm{CDCl}_{3}\right) \delta 145.8,128.5,127.5,125.4,70.4,25.2$.

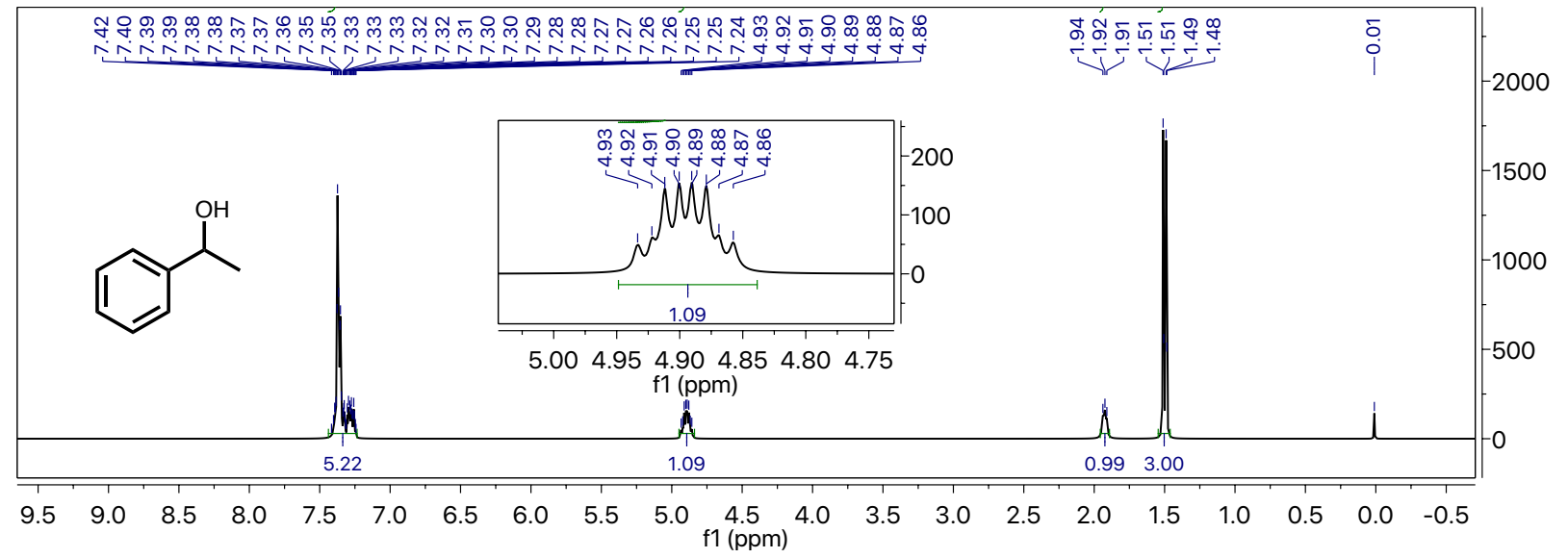




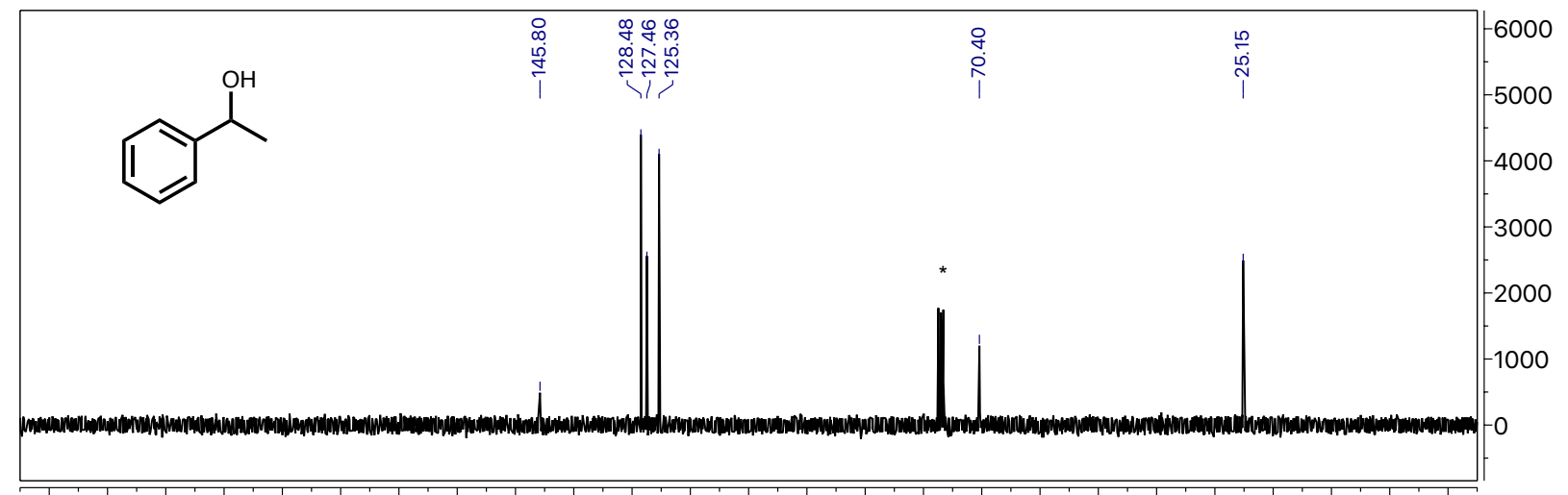

$\begin{array}{lllllllllllllllllllllllllll}230 & 220 & 210 & 200 & 190 & 180 & 170 & 160 & 150 & 140 & 130 & 120 & 110 & 100 & 90 & 80 & 70 & 60 & 50 & 40 & 30 & 20 & 10 & 0 & -10\end{array}$

1-(2-bromophenyl)ethan-1-ol (1bH2). Colorless, clear, viscous oil. (38 mg, 99\% isolated yield). ${ }^{1} \mathrm{H}$ $\operatorname{NMR}\left(300 \mathrm{MHz}, \mathrm{CDCl}_{3} d\right) \delta 7.56(\mathrm{~d}, J=7.8 \mathrm{~Hz}, 1 \mathrm{H}), 7.49(\mathrm{~d}, J=8.0 \mathrm{~Hz}, 1 \mathrm{H}), 7.32(\mathrm{t}, J=7.6 \mathrm{~Hz}, 1 \mathrm{H}), 7.10$ $(\mathrm{t}, J=7.7 \mathrm{~Hz}, 1 \mathrm{H}), 5.2 \mathrm{O}(\mathrm{q}, J=6.4 \mathrm{~Hz}, 1 \mathrm{H}), 2.47(\mathrm{~s}, 1 \mathrm{H}), 1.45$ (d, $J=6.4 \mathrm{~Hz}, 3 \mathrm{H}) .{ }^{13 \mathrm{C}} \mathrm{NMR}\left(75 \mathrm{MHz}, \mathrm{CDCl}_{3}\right)$ $\delta 144.6,132.6,128.7,127.8,126.7,121.7,69.1,23.6$.
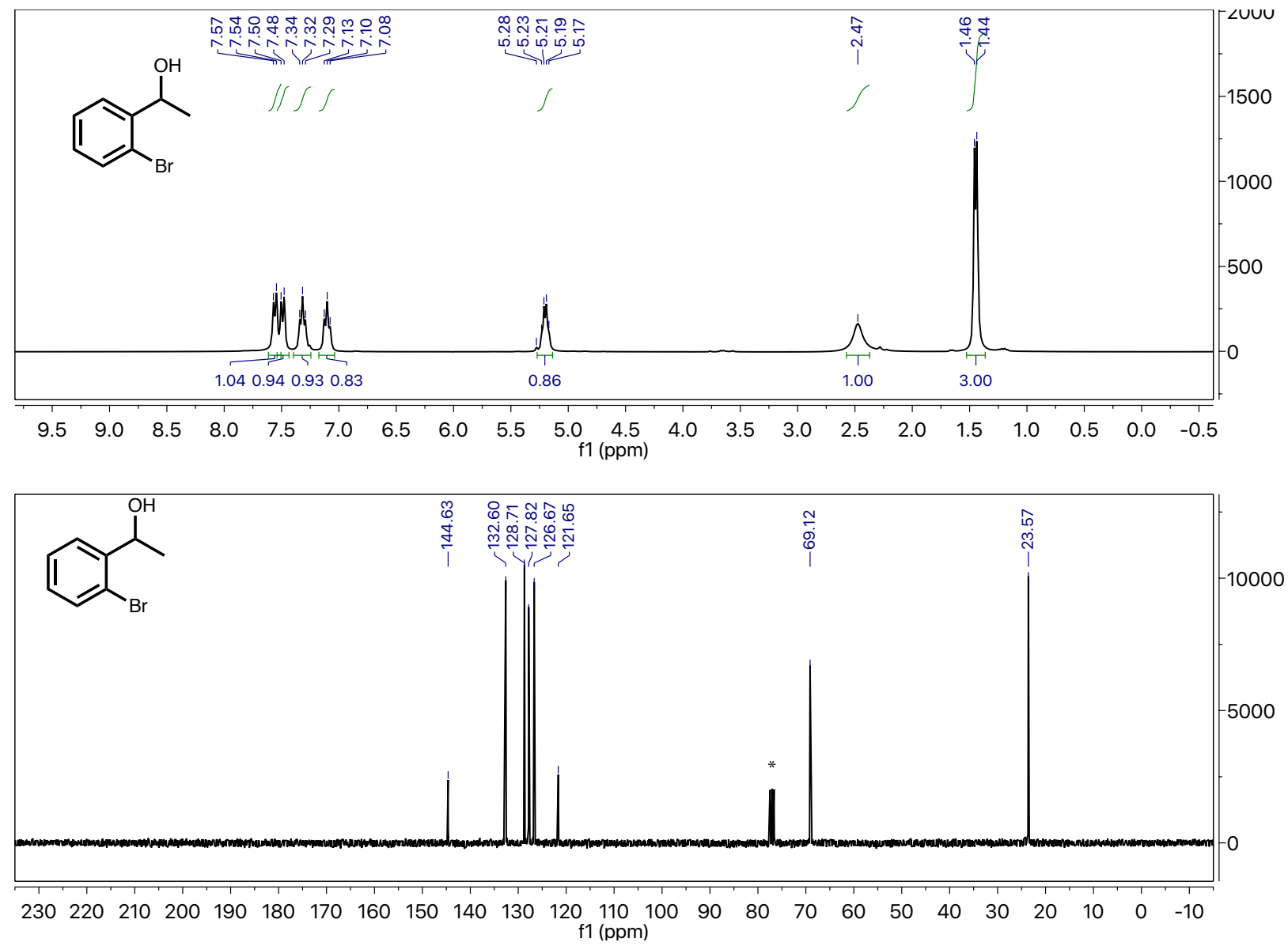

1-(4-methoxyphenyl)ethan-1-ol (1cH2). Colorless, clear oil (25 mg, 84\% isolated yield). ${ }^{1} \mathrm{H}$ NMR (300 $\left.\mathrm{MHz}, \mathrm{CDCl}_{3}\right) \delta 7.28(\mathrm{~d}, J=8.4 \mathrm{~Hz}, 2 \mathrm{H}), 6.87(\mathrm{~d}, J=8.8,2 \mathrm{H}), 4.84(\mathrm{q}, J=6.5 \mathrm{~Hz}, 1 \mathrm{H}), 3.79(\mathrm{~s}, 3 \mathrm{H}), 1.47(\mathrm{~d}$, $J=6.4,3 \mathrm{H}) .{ }^{13 \mathrm{C}} \mathrm{NMR}\left(75 \mathrm{MHz}, \mathrm{CDCl}_{3}\right) \delta$ 158.94, 137.97, 126.64, 113.82, 69.96, 55.28, 24.99. 


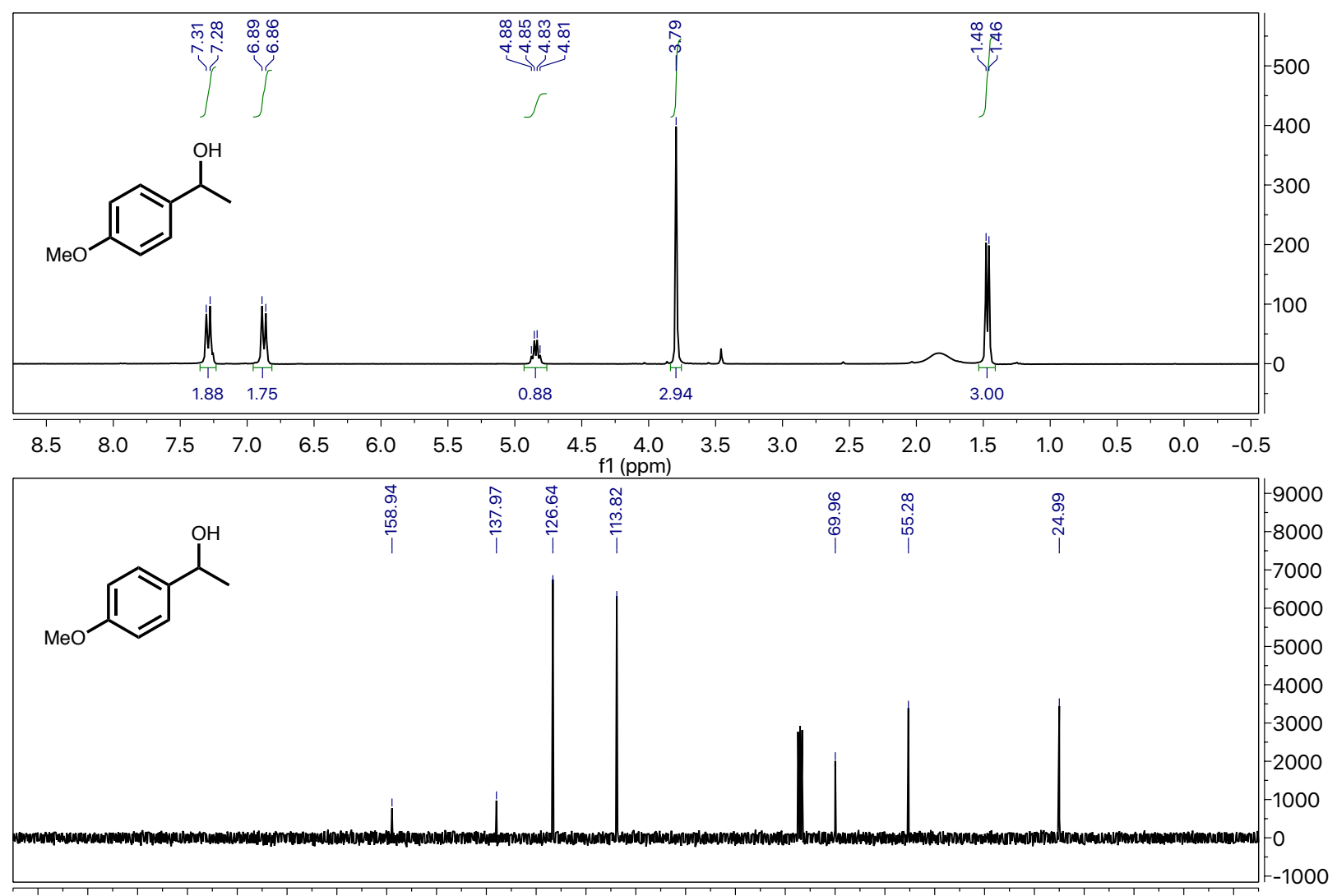

$\begin{array}{lllllllllllllllllllllllll}230 & 220 & 210 & 200 & 190 & 180 & 170 & 160 & 150 & 140 & 130 & 120 & 110 & 100 & 90 & 80 & 70 & 60 & 50 & 40 & 30 & 20 & 10 & 0 & -10\end{array}$

1-(4-nitrophenyl)ethan-1-ol (1dH2). Yellow oil (23 mg, $71 \%$ isolated yield). ${ }^{1} \mathrm{H}$ NMR (300 $\mathrm{MHz}$, $\left.\mathrm{CDCl}_{3}\right) \delta 8.17(\mathrm{~d}, J=8.8 \mathrm{~Hz}, 2 \mathrm{H}), 7.54(\mathrm{~d}, J=8.8 \mathrm{~Hz}, 2 \mathrm{H}), 5.00(\mathrm{qd}, J=6.5,3.2 \mathrm{~Hz}, 1 \mathrm{H}), 1.5 \mathrm{O}(\mathrm{d}, J=6.5$ $\mathrm{Hz}, 3 \mathrm{H}) .{ }^{13 \mathrm{C} \mathrm{NMR}}\left(75 \mathrm{MHz}, \mathrm{CDCl}_{3}\right.$ ) $\delta$ 153.12, 126.10, 123.71, 69.45, 25.47.

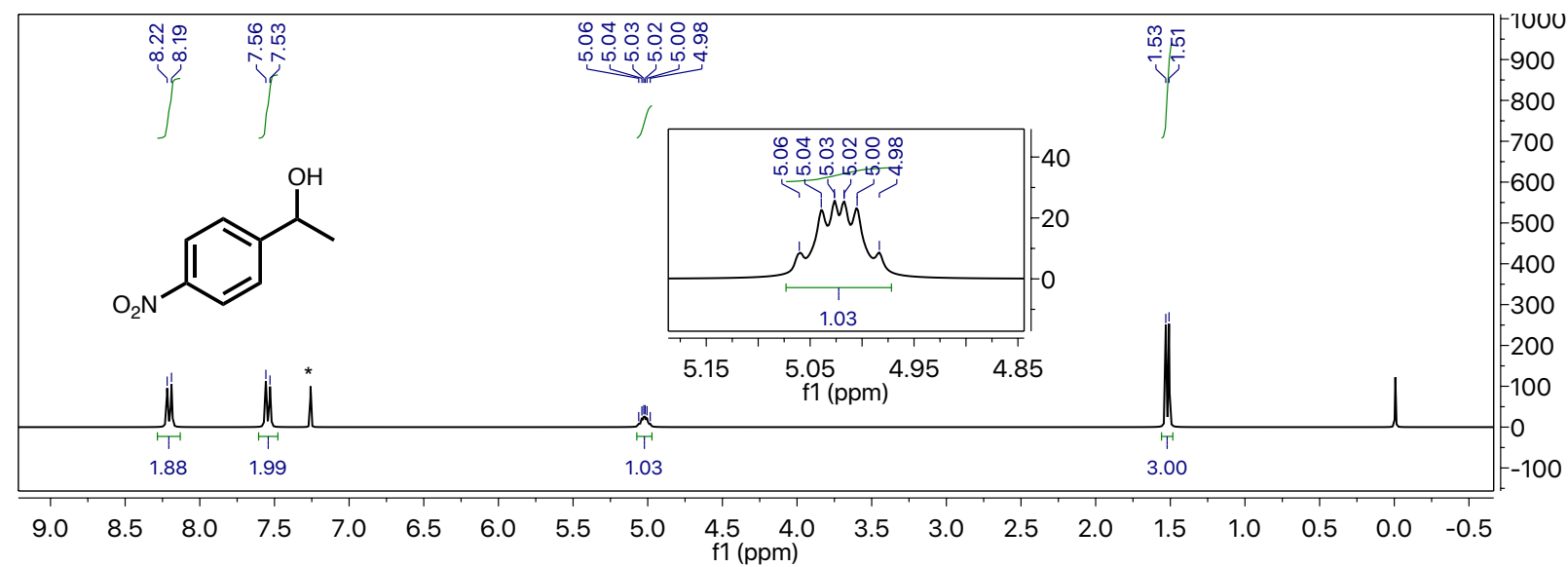




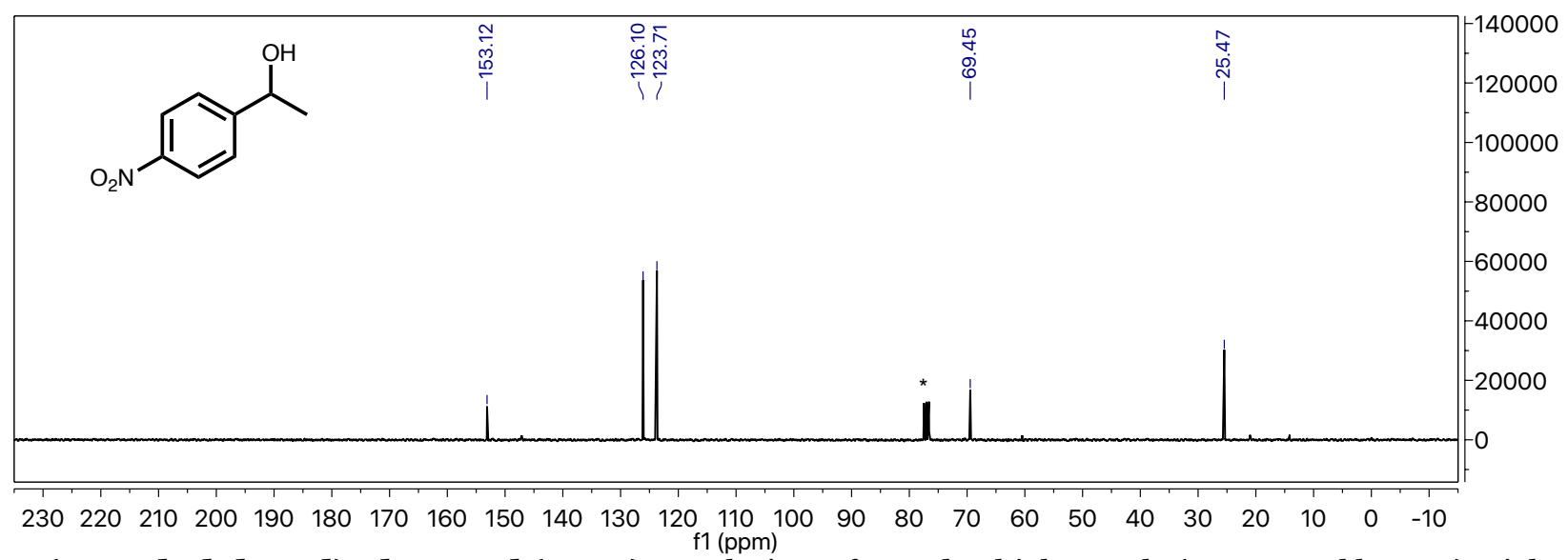

1-(4-methylphenyl)ethan-1-ol (1eH2). Catalysis performed at higher scale (0.38 mmol ketone). Light yellow, clear, light oil (51 mg, 99\% isolated yield). ${ }^{1} \mathrm{H} \mathrm{NMR}\left(300 \mathrm{MHz}, \mathrm{CDCl}_{3}\right) \delta 7.25$ (d, $\left.J=7.8 \mathrm{~Hz}, 2 \mathrm{H}\right)$, $7.15(\mathrm{~d}, J=7.9 \mathrm{~Hz}, 2 \mathrm{H}), 4.83(\mathrm{q}, J=6.5 \mathrm{~Hz}, 1 \mathrm{H}), 2.34(\mathrm{~s}, 3 \mathrm{H}), 1.93(\mathrm{~s}, 1 \mathrm{H}), 1.47(\mathrm{~d}, J=6.5 \mathrm{~Hz}, 3 \mathrm{H}) .{ }^{13} \mathrm{C} \mathrm{NMR}$ $\left(75 \mathrm{MHz}, \mathrm{CDCl}_{3}\right) \delta$ 142.88, 137.10, 129.13, 125.34, 70.21, 25.08, 21.09.
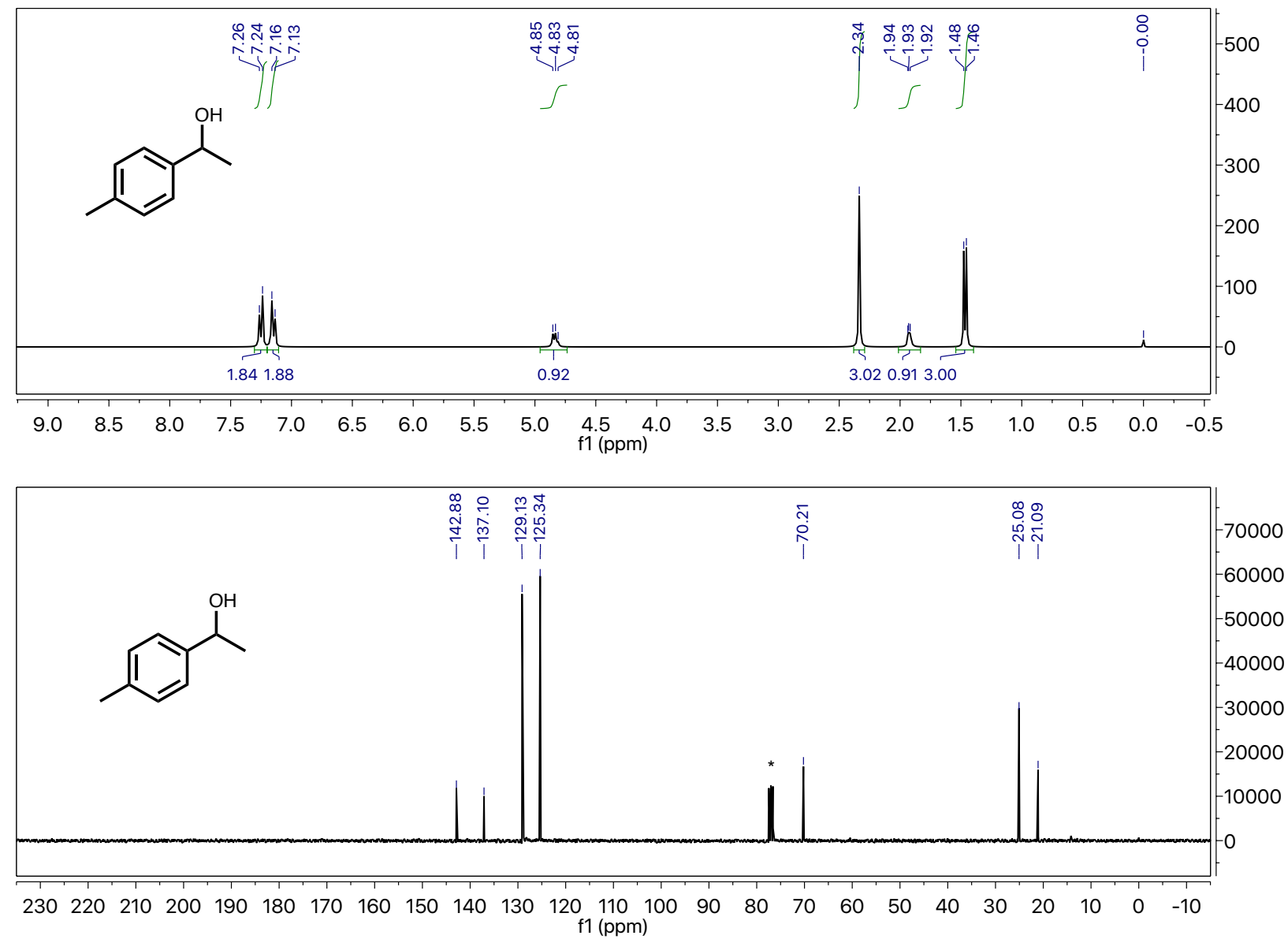

1-(4-(allyloxy)-phenyl)ethan-1-ol (1fH2). Colorless, clear oil (66 mg, 98\% isolated yield). ${ }^{1 \mathrm{H}}$ NMR $\left(400 \mathrm{MHz}, \mathrm{CDCl}_{3}\right) \delta 7.28(\mathrm{~d}, J=8.6 \mathrm{~Hz}, 4 \mathrm{H}), 6.89(\mathrm{~d}, J=8.4 \mathrm{~Hz}, 2 \mathrm{H}), 6.04$ (ddd, $J=16.8,11.6,6.3 \mathrm{~Hz}$, $1 \mathrm{H}), 5.41$ (d, $J=17.3 \mathrm{~Hz}, 1 \mathrm{H}), 5.28$ (d, $J=10.4 \mathrm{~Hz}, 1 \mathrm{H}), 4.85(\mathrm{p}, J=5.9 \mathrm{~Hz}, 1 \mathrm{H}), 4.53(\mathrm{~d}, J=4.1 \mathrm{~Hz}, 3 \mathrm{H})$, $1.46(\mathrm{~d}, J=6.4 \mathrm{~Hz}, 3 \mathrm{H}) .{ }^{13 \mathrm{C}} \mathrm{NMR}\left(101 \mathrm{MHz}, \mathrm{CDCl}_{3}\right) \delta 138.11,133.26,126.62,117.63,114.67,109.99,69.97$, $68.84,24.97$. 


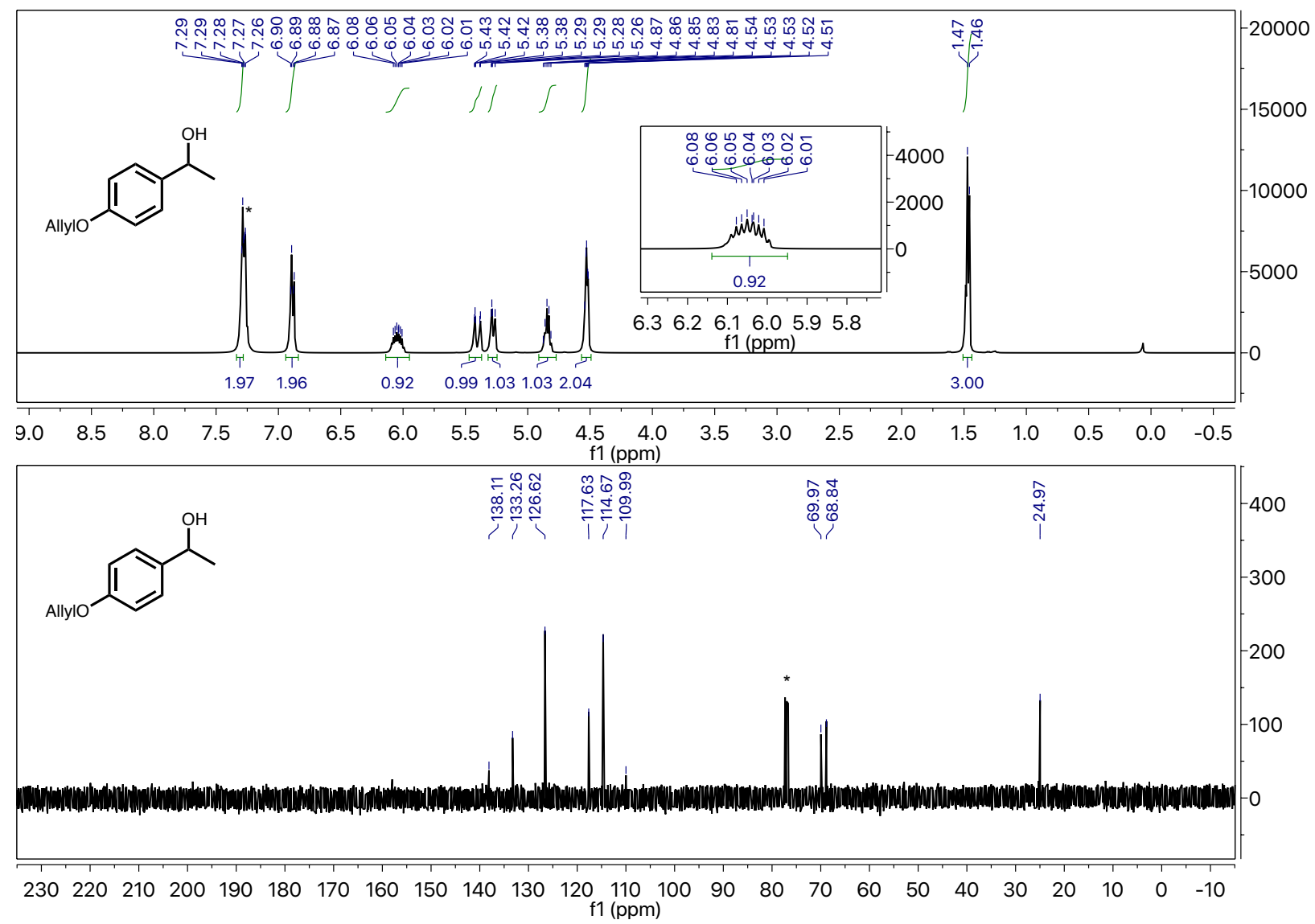

1-(3-(allyloxy)-phenyl)ethan-1-ol (1gH2). Catalysis was performed at higher scale (1.53 mmol ketone). Brown, viscous oil (244 mg, 94\% isolated yield). ${ }^{1} \mathrm{H} \mathrm{NMR}\left(300 \mathrm{MHz}, \mathrm{CDCl}_{3}\right) \delta 7.25(\mathrm{t}, J=7.2 \mathrm{~Hz}$, $1 \mathrm{H}), 6.97-6.92(\mathrm{~m}, 2 \mathrm{H}), 6.82(\mathrm{~d}, J=8.5 \mathrm{~Hz}, 1 \mathrm{H}), 6.06(\mathrm{tdd}, J=16.1,11.2,6.2 \mathrm{~Hz}, 1 \mathrm{H}), 5.42(\mathrm{~d}, J=17.3 \mathrm{~Hz}$, $1 \mathrm{H}), 5.28(\mathrm{~d}, J=10.5 \mathrm{~Hz}, 1 \mathrm{H}), 4.87(\mathrm{q}, J=6.4 \mathrm{~Hz}, 1 \mathrm{H}), 4.55(\mathrm{~d}, J=5.1 \mathrm{~Hz}, 2 \mathrm{H}), 1.83(\mathrm{~s}, 1 \mathrm{H}), 1.48(\mathrm{~d}, J=6.7$ $\mathrm{Hz}, 3 \mathrm{H}) .{ }^{13 \mathrm{C}} \mathrm{NMR}\left(75 \mathrm{MHz}, \mathrm{CDCl}_{3}\right) \delta 158.78,147.54,133.24,129.5 \mathrm{O}, 117.82,117.65,113.61,111.77,70.32$, $68.75,25.11$.

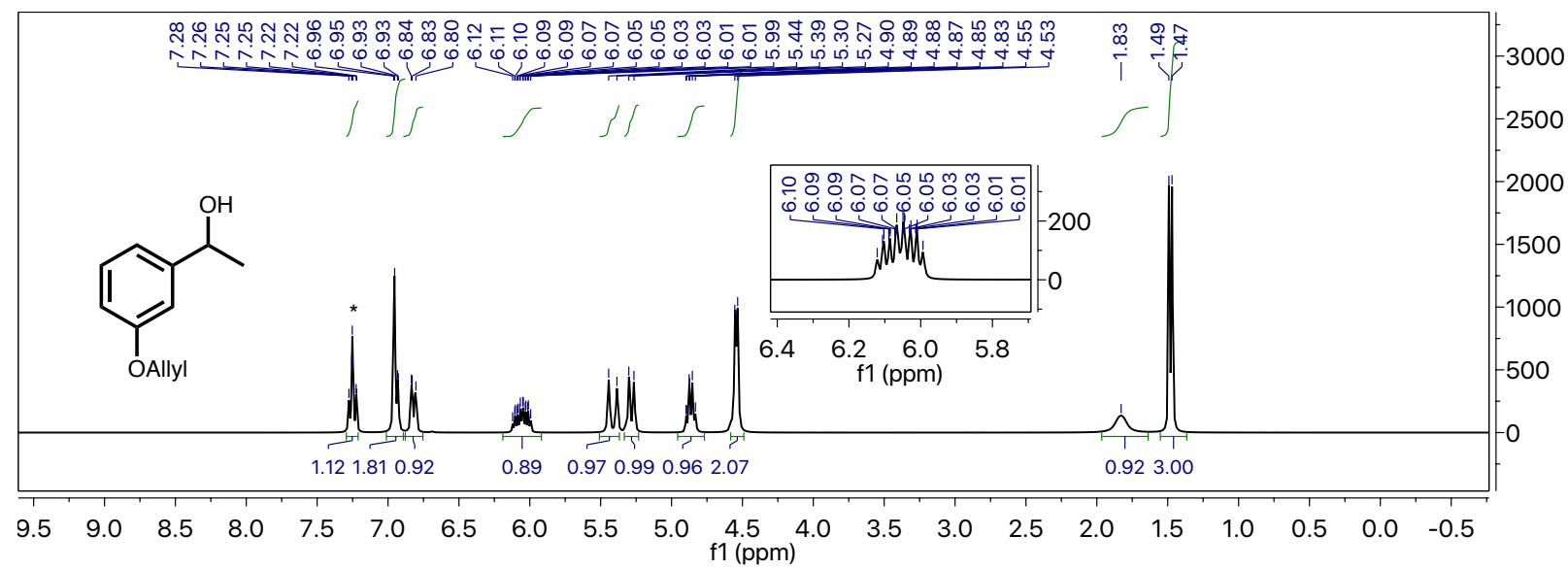




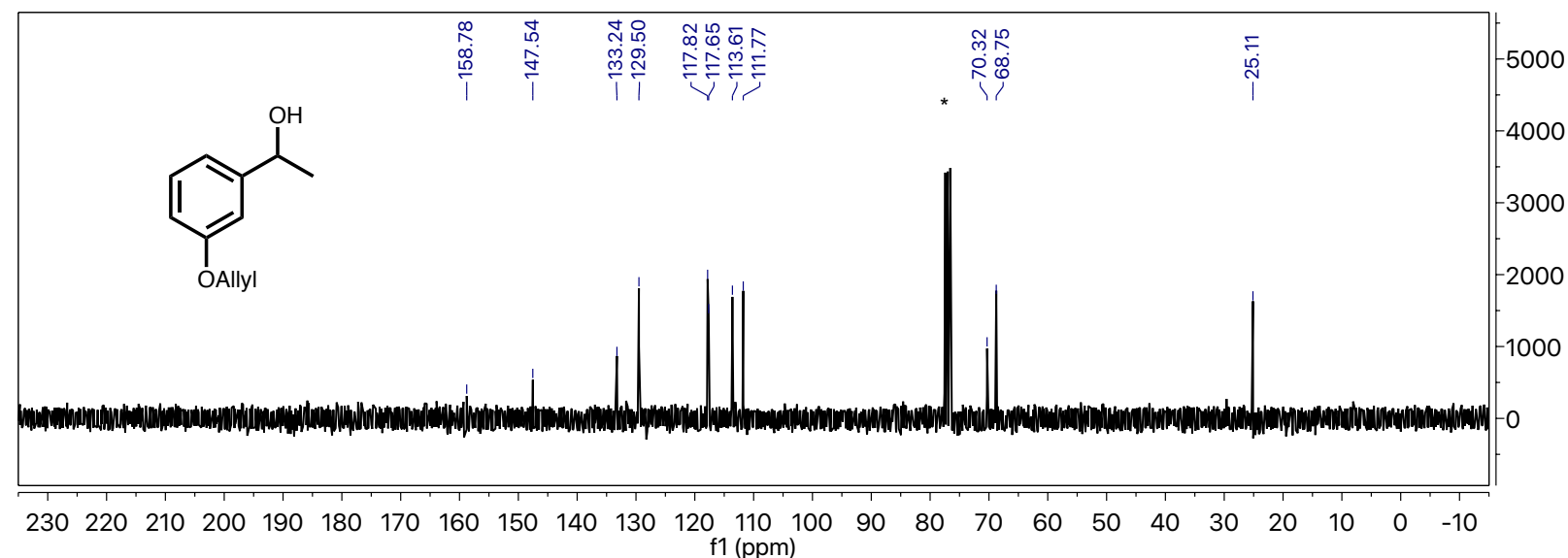

1,2-diphenylethan-1-ol (1iH2). White solid. (33 mg, 87\% isolated yield). ${ }^{1} \mathrm{H}$ NMR (3Oo $\mathrm{MHz}, \mathrm{CDCl}_{3}$ ) $\delta$ $=7.37-7.19(\mathrm{~m}, 1 \mathrm{OH}, \mathrm{Ar}-H), 4.91(\mathrm{q}, 1 \mathrm{H}, \mathrm{C}-\mathrm{H}), 2.99(\mathrm{~m}, 2 \mathrm{H}, \mathrm{C}-H), 1.95(\mathrm{sh} \mathrm{s}, 1 \mathrm{H}, \mathrm{O}-H) .{ }^{13 \mathrm{C}} \mathrm{NMR}(75 \mathrm{MHz}$, $\left.\mathrm{CDCl}_{3}\right) \delta=143.8,138.0,129.5,128.5,128.4,127.6,126.6,125.9,75 \cdot 3$, 46.1. (+ denotes residual ethyl acetate).
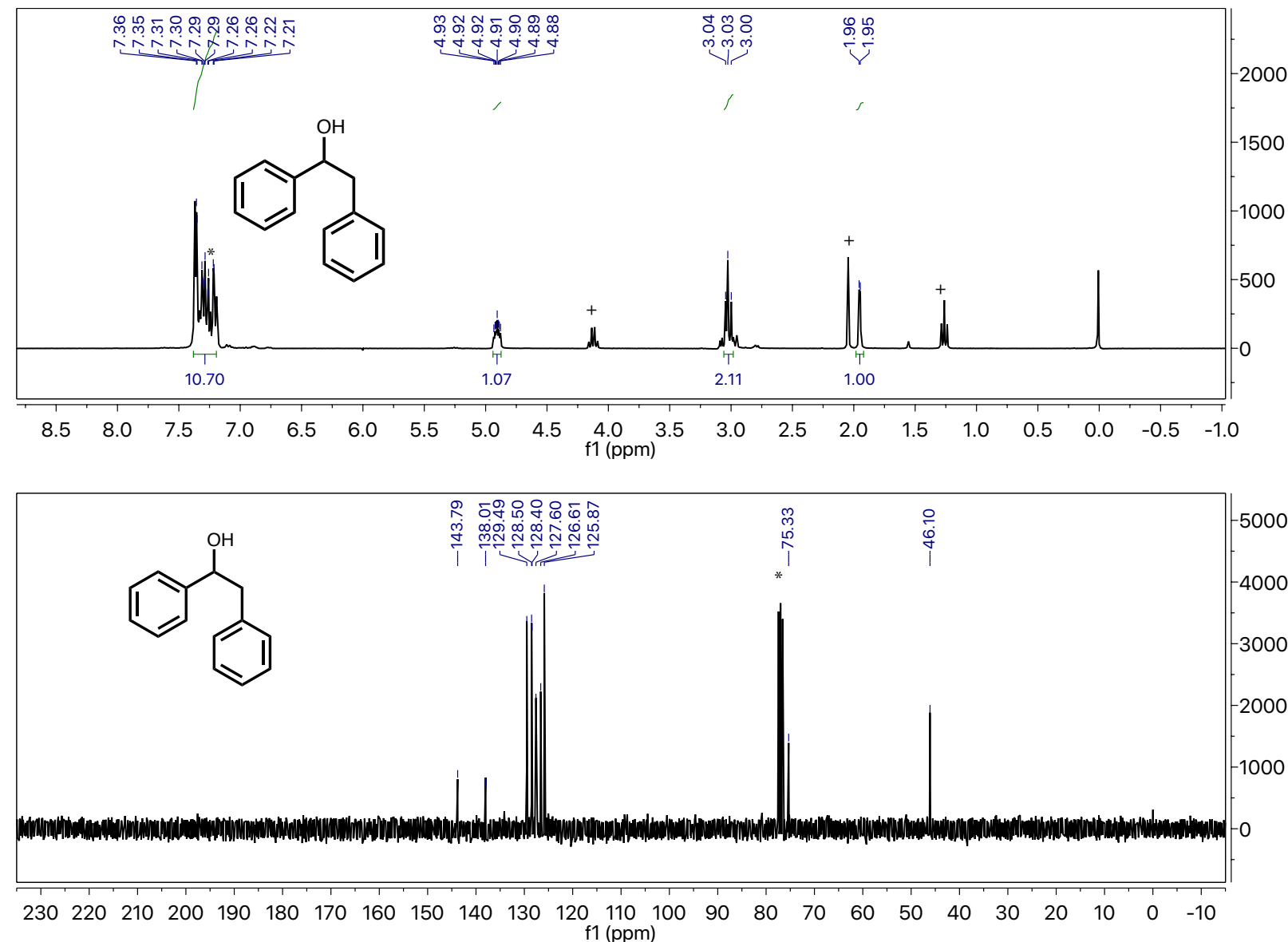

(4-bromophenyl)(phenyl)methanol (2aH2). Off-white solid (41 mg, 84\% isolated yield). ${ }^{1} \mathrm{H}$ NMR $\left(300 \mathrm{MHz}, \mathrm{CDCl}_{3}\right) \delta 7.46(\mathrm{~d}, J=8.5 \mathrm{~Hz}, 2 \mathrm{H}), 7.35-7.27(\mathrm{~m}, 5 \mathrm{H}), 7.26(\mathrm{~d}, J=8.2 \mathrm{~Hz}, 2 \mathrm{H}), 5.79(\mathrm{~d}, J=3.5$ $\mathrm{Hz}, 2 \mathrm{H}), 2.26(\mathrm{~s}, 1 \mathrm{H}) .{ }^{13 \mathrm{C}} \mathrm{NMR}\left(75 \mathrm{MHz}, \mathrm{CDCl}_{3}\right) \delta=143.3,142.7,131.5,128.6,128.2,127.9,126.5 .121 .4$, 75.6 . 


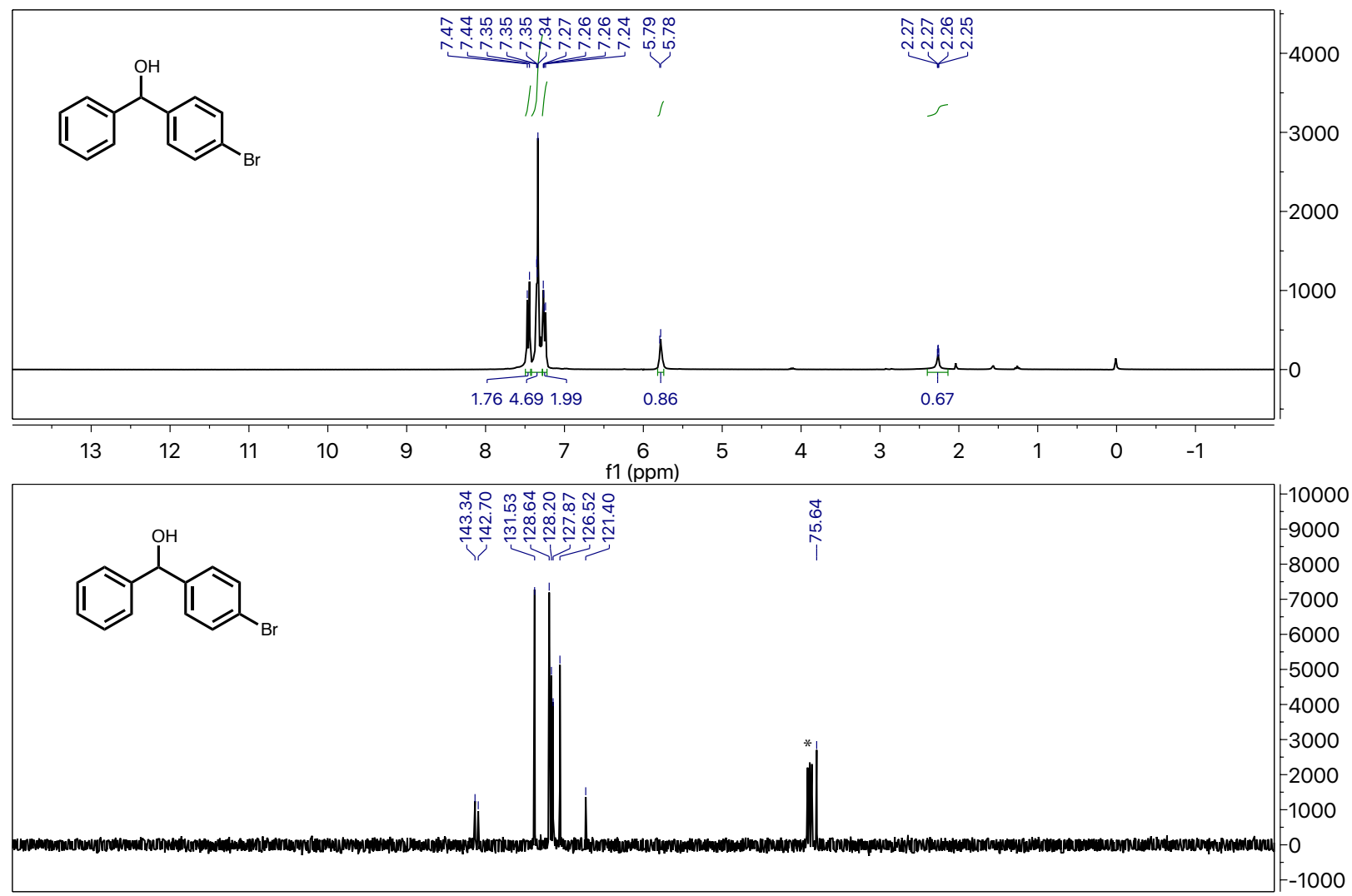

$\begin{array}{llllllllllllllllllllllllll}230 & 220 & 210 & 200 & 190 & 180 & 170 & 160 & 150 & 140 & 130 & 120 & 110 & 100 & 90 & 80 & 70 & 60 & 50 & 40 & 30 & 20 & 10 & 0 & -10\end{array}$

Diphenylmethanol (2bH2). White solid (182 mg, 99\% isolated yield). ${ }^{1} \mathrm{H}$ NMR (300 $\left.\mathrm{MHz}, \mathrm{CDCl}_{3}\right) \delta$ 7.40-7.23 (m, 10H), $5.85(\mathrm{~d}, J=3.4 \mathrm{~Hz}, 1 \mathrm{H}), 2.22(\mathrm{~d}, J=3.5 \mathrm{~Hz}, 1 \mathrm{H}) .{ }^{13} \mathrm{C}$ NMR $\left(75 \mathrm{MHz}, \mathrm{CDCl}_{3}\right) \delta 143.8$, $128.5,127.6,126.5,76.3$.

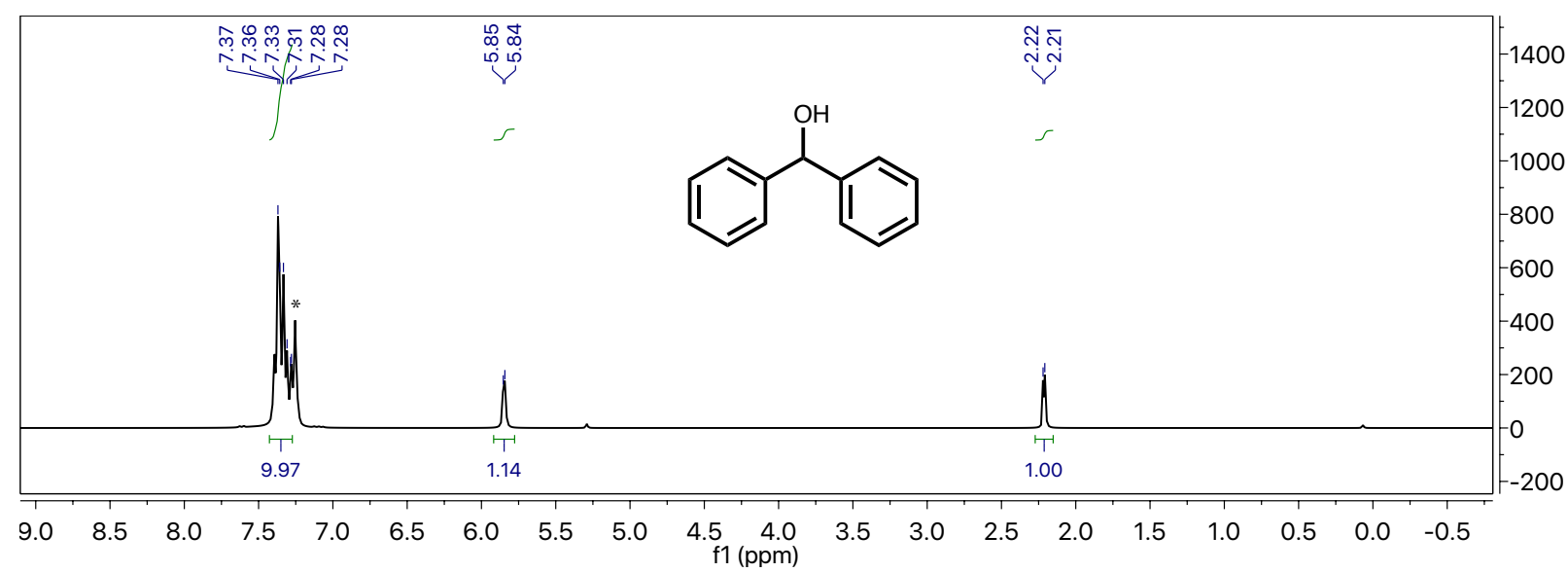




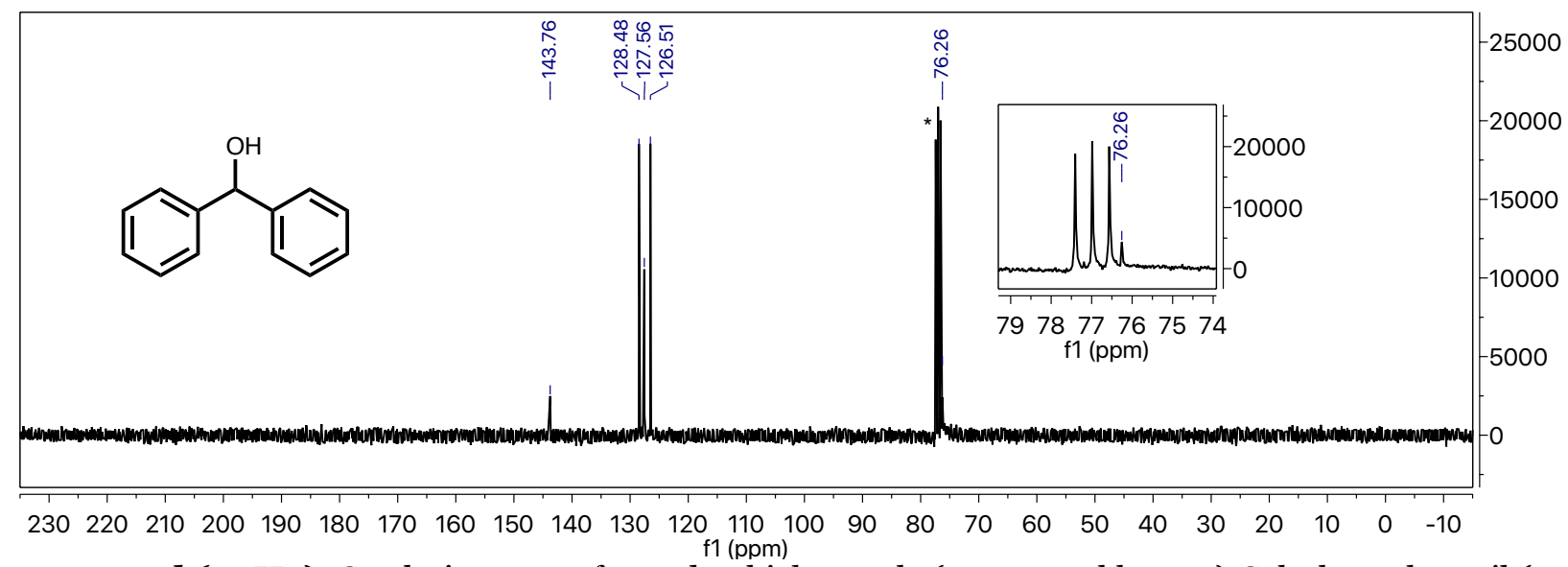

2-octanol (3aH2). Catalysis was performed at higher scale (0.95 mmol ketone) Colorless, clear oil (111 $\mathrm{mg}, 90 \%$ isolated yield, isolated through silica plug with hexane). ${ }^{1} \mathrm{H} \mathrm{NMR}\left(300 \mathrm{MHz}, \mathrm{CDCl}_{3}\right) \delta=3.77$ (q, $1 \mathrm{H}, \mathrm{C}-\mathrm{H}), 1.41-1.25\left(\mathrm{~m}, 12 \mathrm{H}, \mathrm{C}-\mathrm{H}_{2}\right), 1.17\left(\mathrm{~d}, 3 \mathrm{H}, \mathrm{C}-\mathrm{H}_{3}\right), 0.85\left(\mathrm{~d}, 3 \mathrm{H}, \mathrm{C}-\mathrm{H}_{3}\right) .{ }^{13 \mathrm{C}} \mathrm{NMR}\left(75 \mathrm{MHz}, \mathrm{CDCl}_{3}\right) \delta=$ 68.1, 39.4, 31.8, 29.3, 25.1, 23.4, 22.6, 14.0.
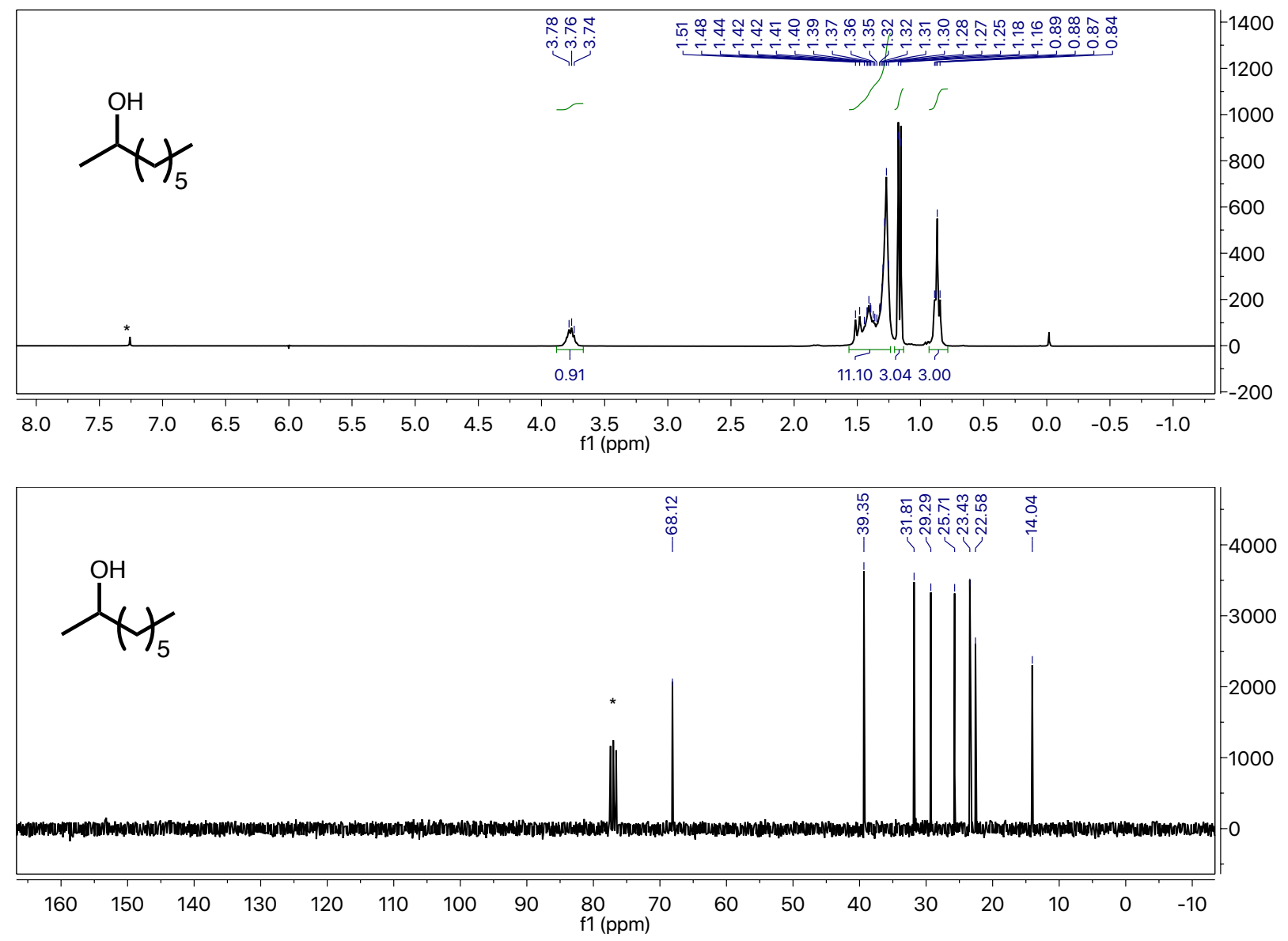

Cyclohexanol (3bH2). Colorless semi-solid - solidifies on standing. (193 mg, 99\% isolated yield). ${ }^{1} \mathrm{H}$ $\mathrm{NMR}\left(300 \mathrm{MHz}, \mathrm{CDCl}_{3}\right) \delta 3.60(\mathrm{dp}, J=8.8,4.2 \mathrm{~Hz}, 1 \mathrm{H}), 2.03-1.83(\mathrm{~m}, 2 \mathrm{H}), 1.83-1.63(\mathrm{~m}, 2 \mathrm{H}), 1.57-$ $1.48(\mathrm{~m}, 3 \mathrm{H}), 1.35-1.16(\mathrm{~m}, 5 \mathrm{H}) .{ }^{13} \mathrm{C} \mathrm{NMR}\left(75 \mathrm{MHz}, \mathrm{CDCl}_{3}\right) \delta$ 70.33, 35.53, 25.43, 24.11. 


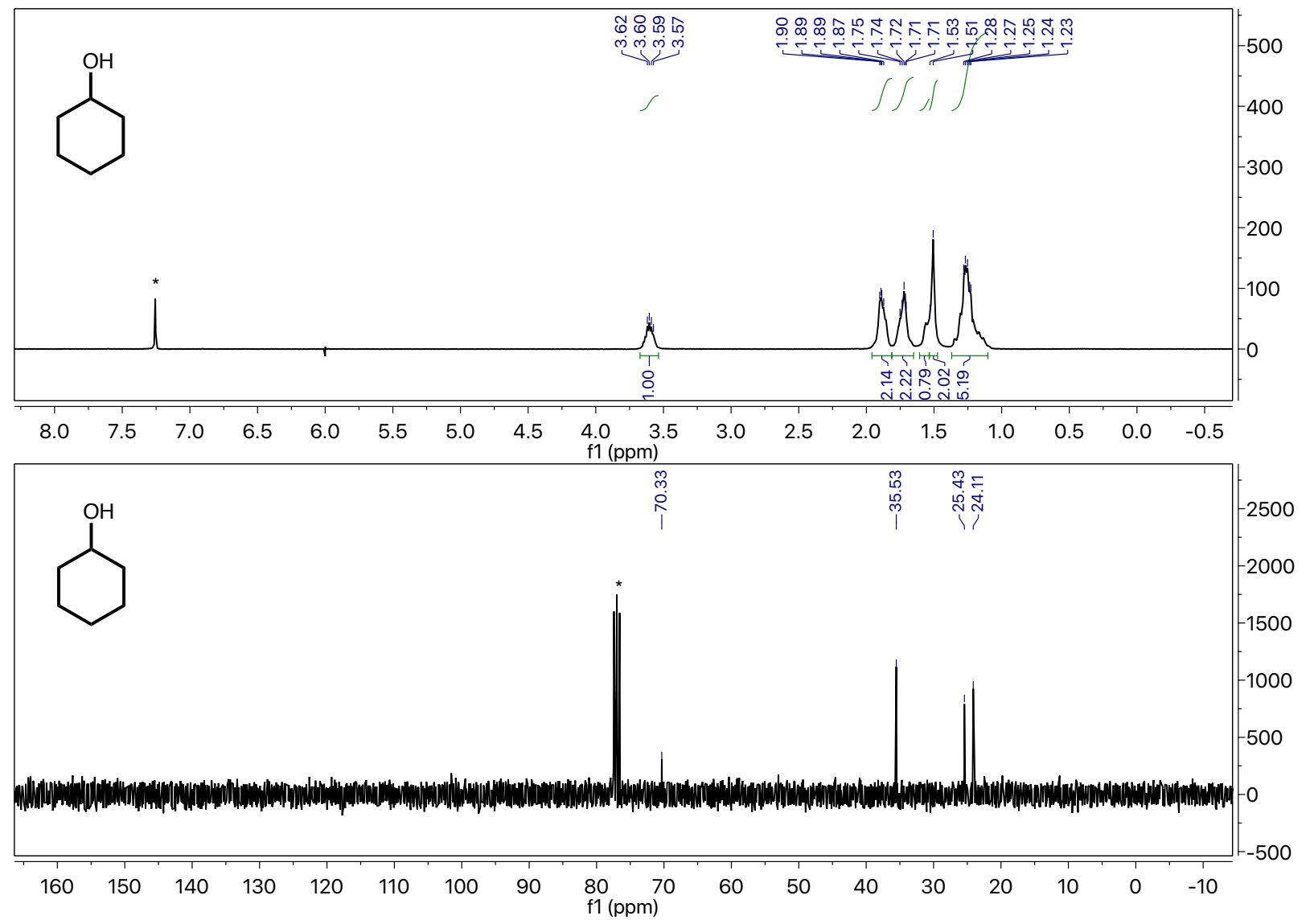

1-(thiophen-2-yl)ethan-1-ol (4aH2). Colorless, clear oil (19 mg, 85\% isolated yield). ${ }^{1} \mathrm{H}$ NMR (300 $\left.\mathrm{MHz}, \mathrm{CDCl}_{3}\right) \delta 7.34-7.13(\mathrm{~m}, 1 \mathrm{H}), 7.07-6.90(\mathrm{~m}, 2 \mathrm{H}), 5.13(\mathrm{q}, J=6.4 \mathrm{~Hz}, 1 \mathrm{H}), 2.00(\mathrm{~s}, 1 \mathrm{H}), 1.60(\mathrm{~d}, J=$ $6.4 \mathrm{~Hz}, 3 \mathrm{H}) .{ }^{13 \mathrm{C}} \mathrm{NMR}\left(75 \mathrm{MHz}, \mathrm{CDCl}_{3}\right) \delta 149.8,126.6,124.4,123.2,66.3,25 \cdot 3$.

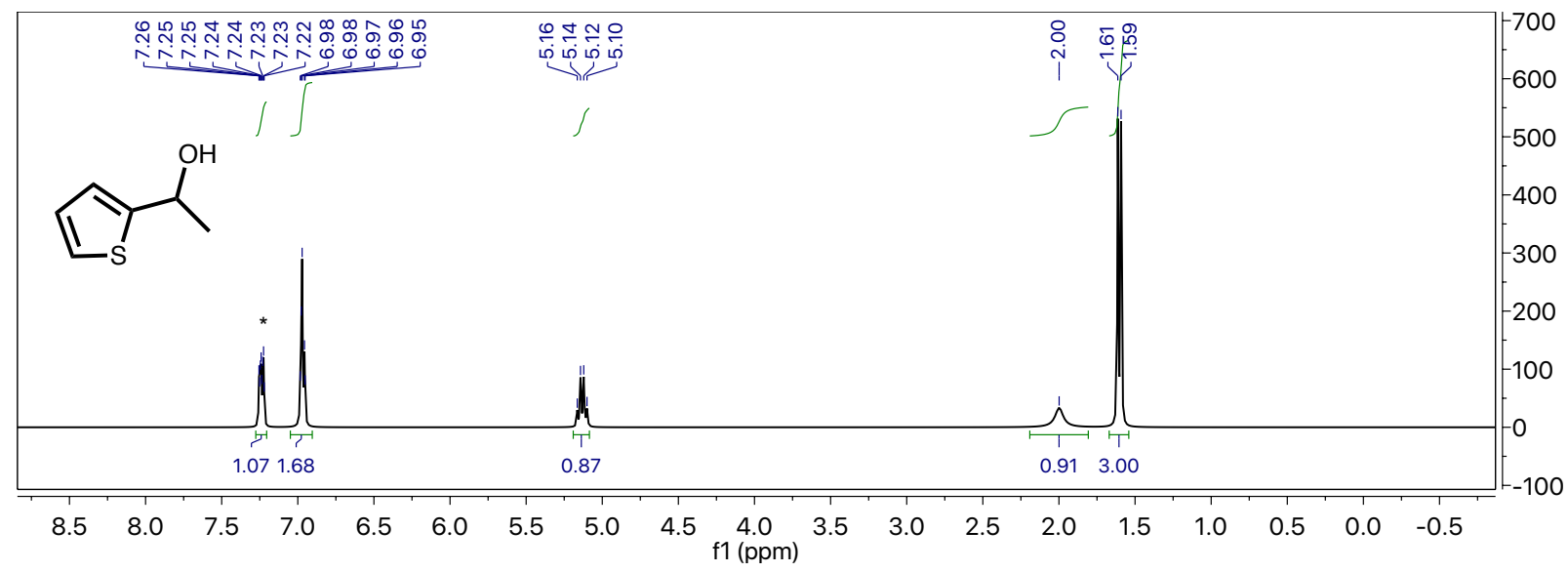




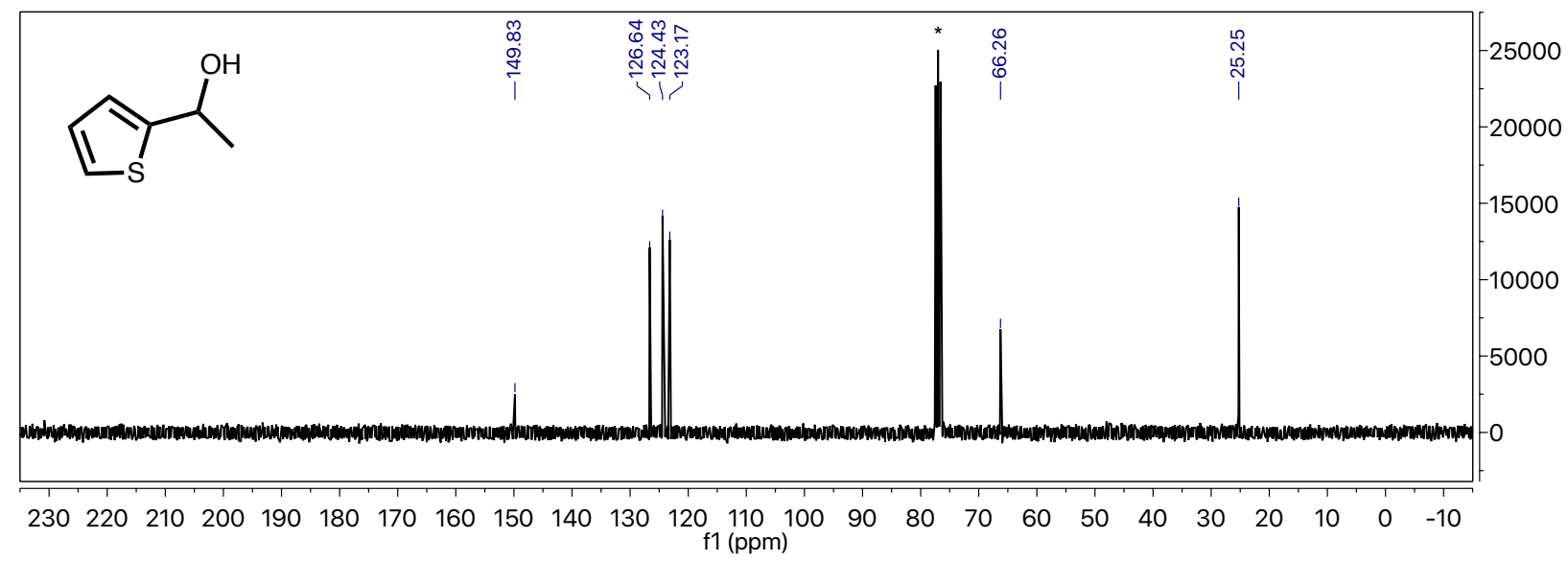

1-(furan-2-yl)ethan-1-ol (4bH2). Catalysis was performed at a higher scale (Ketone - 0.38 mmol). Colorless, clear, light oil (26 mg, 63\% isolated yield). ${ }^{1} \mathrm{H}$ NMR (300 MHz, $\left.\mathrm{CDCl}_{3}\right) \delta=7.36(\mathrm{~d}, 1 \mathrm{H}, \mathrm{Ar}-H)$, $6.32(\mathrm{~d}, 1 \mathrm{H}, \mathrm{Ar}-H), 6.21(\mathrm{dd}, 1 \mathrm{H}, \mathrm{Ar}-H), 4.87(\mathrm{q}, 1 \mathrm{H}, \mathrm{C}-\mathrm{H}), 2.08(\mathrm{br} \mathrm{s}, 1 \mathrm{H}, \mathrm{O}-\mathrm{H}), 1.53\left(\mathrm{~d}, 3 \mathrm{H}, \mathrm{C}-\mathrm{H}_{3}\right) .{ }_{13 \mathrm{C}} \mathrm{NMR}$ $\left(75 \mathrm{MHz}, \mathrm{CDCl}_{3}\right) \delta=157.6,141.2,110.1,105.0,63.5,21.2$. (Peaks denoted by + from residual ethyl acetate).

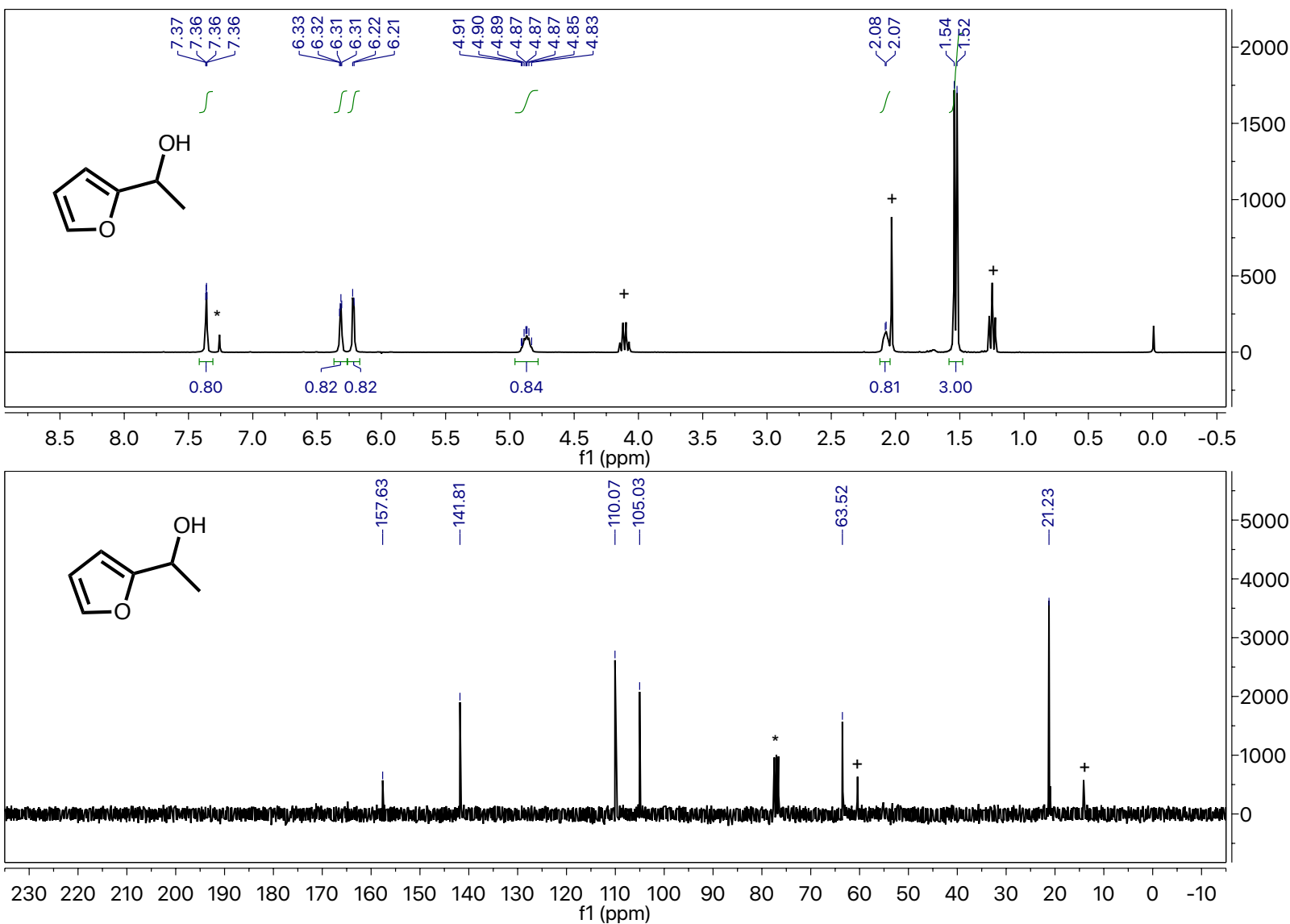

1-(thiophen-3-yl)ethan-1-ol (4cH2). Colorless, clear oil (22 mg, 89\% isolated yield). ${ }^{1 \mathrm{H}} \mathrm{NMR}$ (300 $\left.\mathrm{MHz}, \mathrm{CDCl}_{3}\right) \delta 7.30(\mathrm{dt}, J=5.5,2.8 \mathrm{~Hz}, 1 \mathrm{H}), 7.19(\mathrm{~d}, J=3.1 \mathrm{~Hz}, 1 \mathrm{H}), 7.12-7.07(\mathrm{~m}, 1 \mathrm{H}), 4.96(\mathrm{q}, J=6.5$ $\mathrm{Hz}, 1 \mathrm{H}), 1.52$ (d, $J=6.4 \mathrm{~Hz}, 3 \mathrm{H}) .{ }^{13 \mathrm{C}} \mathrm{NMR}\left(75 \mathrm{MHz}, \mathrm{CDCl}_{3}\right) \delta 147.27,126.15,125.59,120.15,66.55,24.45$. 


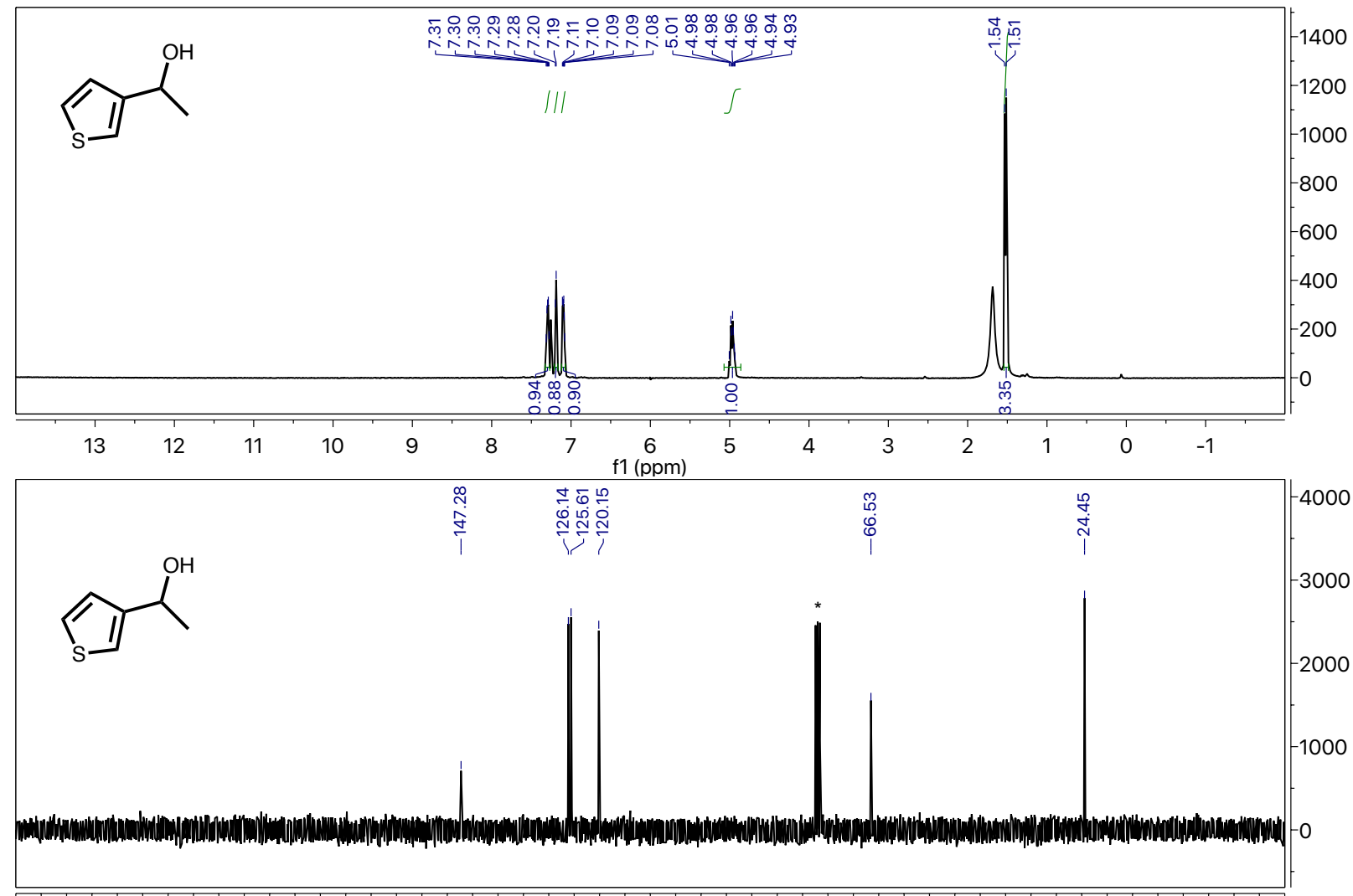

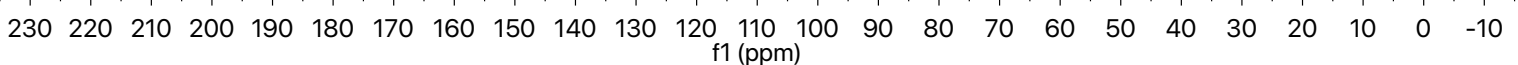

1-(pyridin-4-yl)ethan-1-ol (4dH2). Pale yellow oil (22 mg, $47 \%$ isolated yield). ${ }^{1} \mathrm{H}$ NMR (300 MHz, $\left.\mathrm{CDCl}_{3}\right) \delta 8.35(\mathrm{~d}, J=5.2 \mathrm{~Hz}, 2 \mathrm{H}), 7.25(\mathrm{~d}, J=5.2 \mathrm{~Hz}, 2 \mathrm{H}), 4.83(\mathrm{q}, J=6.6 \mathrm{~Hz}, 1 \mathrm{H}), 4.59(\mathrm{br} \mathrm{s}, 1 \mathrm{H}), 1.42(\mathrm{~d}, J=6.6$ $\mathrm{Hz}, 3 \mathrm{H}) .{ }^{13 \mathrm{C}} \mathrm{NMR}\left(75 \mathrm{MHz}, \mathrm{CDCl}_{3}\right) \delta=155.5,149.1,120.6,68.3$, 25.0. (+ denotes residual ethyl acetate).

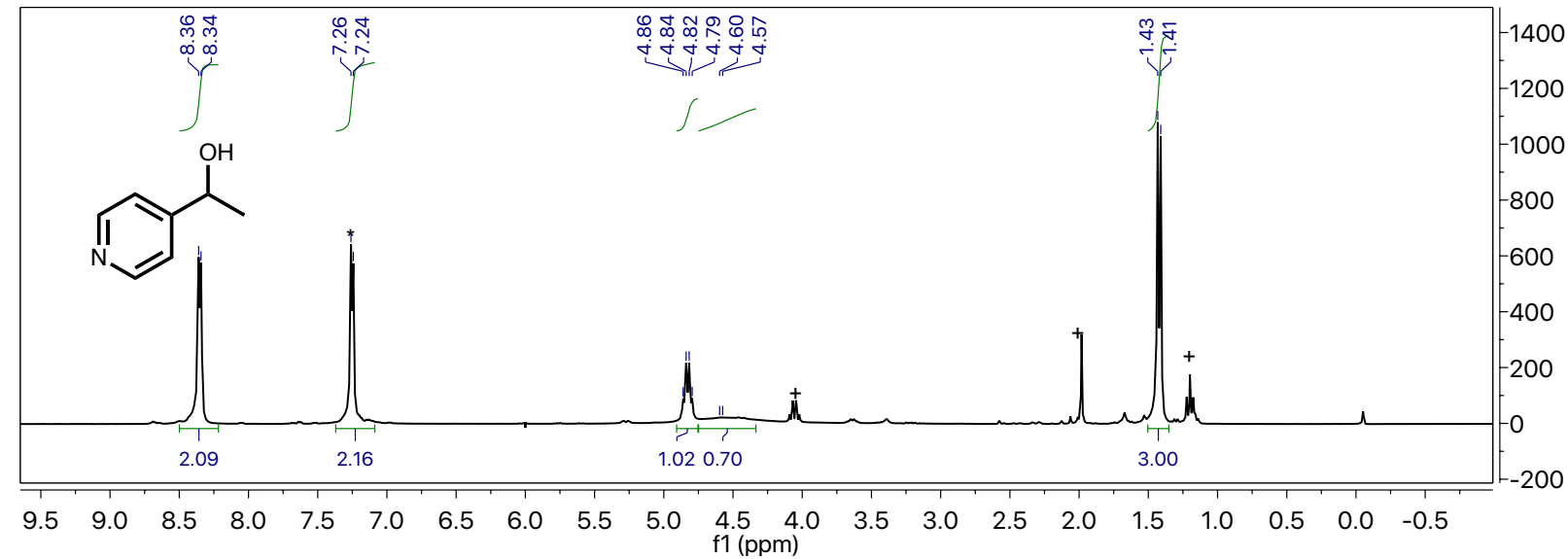




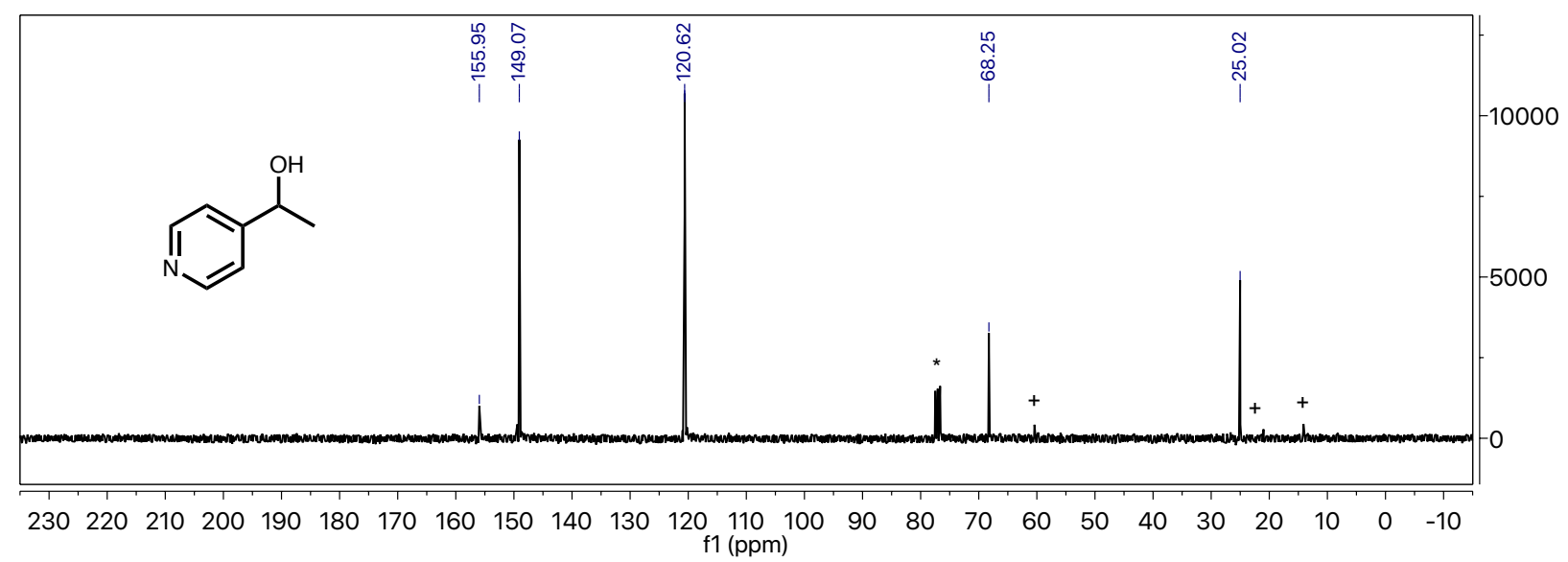

1,3-diphenylpropan-1-one (7aH2). Pale, yellow solid ( $68 \mathrm{mg}, 84 \%$ isolated yield) ${ }^{1} \mathrm{H} \mathrm{NMR} \mathrm{(400} \mathrm{MHz,}$ $\left.\mathrm{CDCl}_{3}\right) \delta 7.99(\mathrm{~d}, J=7.7 \mathrm{~Hz}, 2 \mathrm{H}), 7.45(\mathrm{t}, J=7.7 \mathrm{~Hz}, 2 \mathrm{H}), 7.35(\mathrm{~d}, J=4.3 \mathrm{~Hz}, 1 \mathrm{H}), 7.33-7.23(\mathrm{~m}, 4 \mathrm{H}), 7.22$ $-7.17(\mathrm{~m}, 1 \mathrm{H}), 3.3 \mathrm{O}(\mathrm{t}, J=7.7 \mathrm{~Hz}, 2 \mathrm{H}), 3.07(\mathrm{t}, J=7.7 \mathrm{~Hz}, 2 \mathrm{H}) .{ }^{13 \mathrm{C}} \mathrm{NMR}\left(75 \mathrm{MHz}, \mathrm{CDCl}_{3}\right) \delta=199.2,141.3$, $133.1,128.6,128.5,128.4,128.0,128.1,40.5,30.1$.

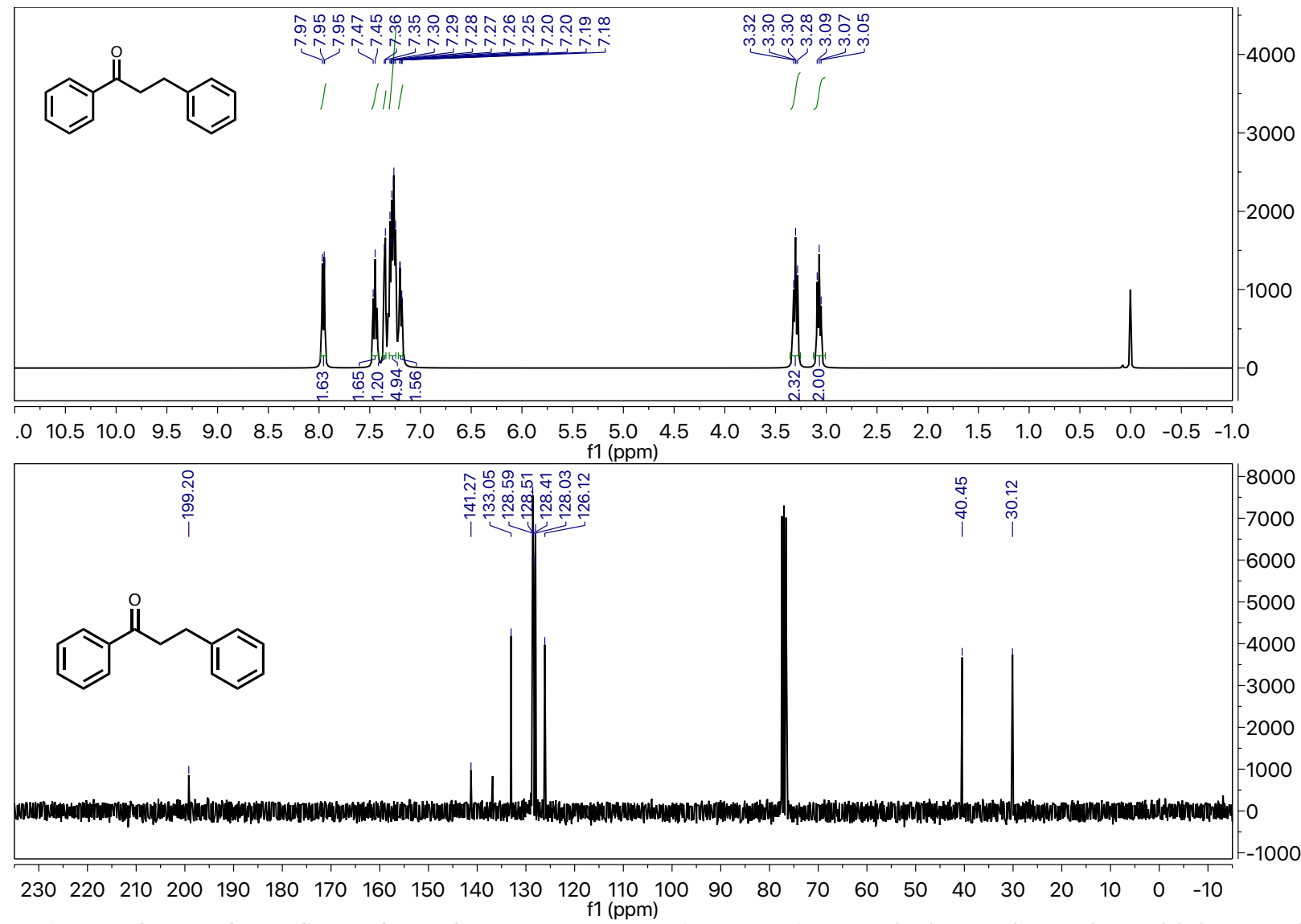

1-(4-methoxyphenyl)-3-phenylpropan-1-one (7a-OMe). Catalysis performed at higher scale (chalcone - $0.764 \mathrm{mmol}$ ) White, crystalline solid (178 mg, 97\% isolated yield). ${ }^{1} \mathrm{H} \mathrm{NMR}\left(300 \mathrm{MHz}, \mathrm{CDCl}_{3}\right)$ $\delta 7.95(\mathrm{~d}, J=8.8 \mathrm{~Hz}, 2 \mathrm{H}), 7.36-7.19(\mathrm{~m}, 5 \mathrm{H}), 6.92(\mathrm{~d}, J=8.7 \mathrm{~Hz}, 2 \mathrm{H}), 3.86$ (s, $3 \mathrm{H}), 3.25$ (dd, $J=8.6,6.7$ $\mathrm{Hz}, 2 \mathrm{H}), 3.06$ (t, $J=7.7 \mathrm{~Hz}, 2 \mathrm{H}) .{ }^{13 \mathrm{C}} \mathrm{NMR}\left(75 \mathrm{MHz}, \mathrm{CDCl}_{3}\right) \delta 197.8,163.4,141.5,130.3,128.5,128.4,126.1$, $113.7,55.4,40.1,30.3$. 


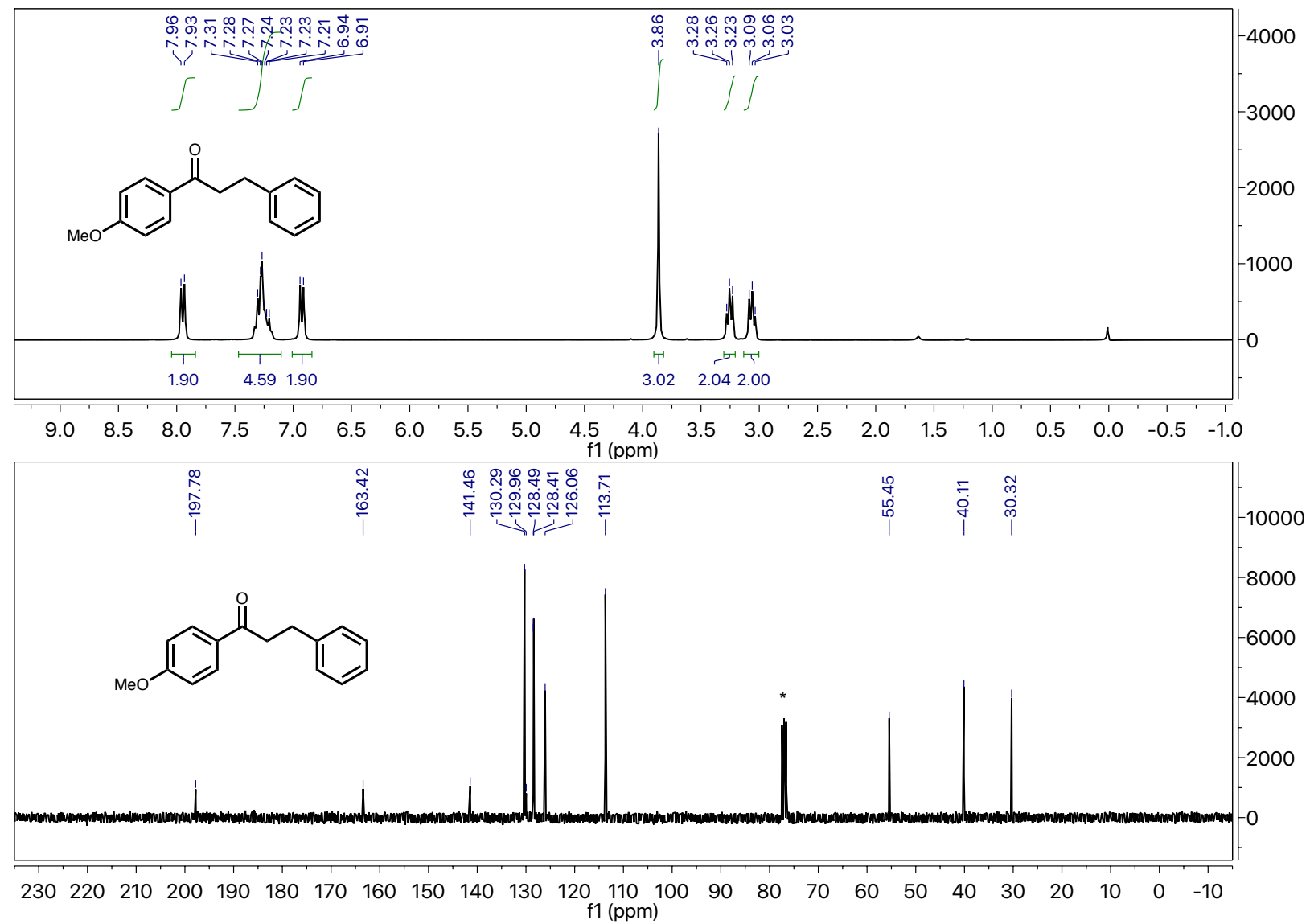

3-phenyl-1-(p-tolyl)propan-1-one (7a-Me). Pale, yellow solid (74 mg, $78 \%$ isolated yield). ${ }^{1} \mathrm{H}$ NMR $\left(300 \mathrm{MHz}, \mathrm{CDCl}_{3}\right) \delta 7.86(\mathrm{~d}, J=8.2 \mathrm{~Hz}, 2 \mathrm{H}), 7.42-7.05(\mathrm{~m}, 7 \mathrm{H}), 3.27(\mathrm{dt}, J=6.6,4.4 \mathrm{~Hz}, 1 \mathrm{H}), 3.06(\mathrm{t}, J$ $=4.2 \mathrm{~Hz}, 1 \mathrm{H}), 2.40(\mathrm{~d}, J=2.5 \mathrm{~Hz}, 3 \mathrm{H})$.

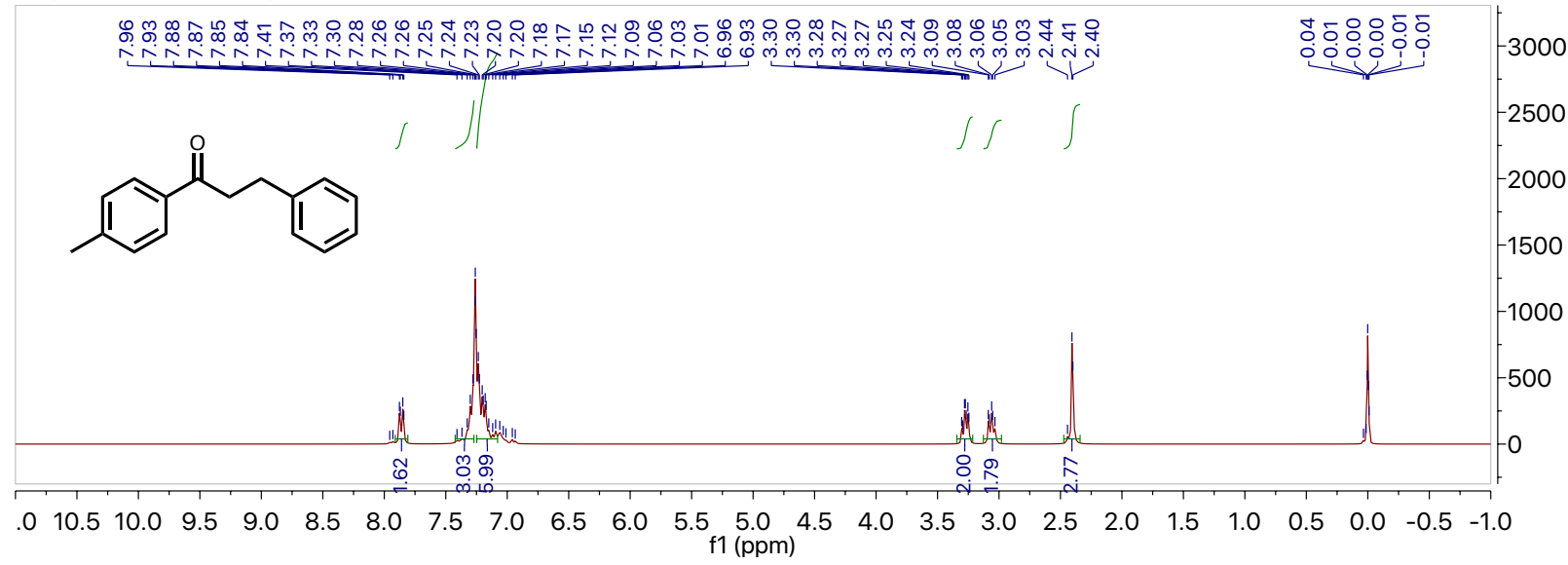

2-benzyl-2,3-dihydro-1H-inden-1-one (9). Brown oil, solidifies on standing. (178 $\mathrm{mg}$, 70\% isolated yield, passed through silica plug with DCM:hexane (50:50) ${ }^{1} \mathrm{H} \mathrm{NMR}(300 \mathrm{MHz},) \delta 7.79(\mathrm{~d}, J=7.7 \mathrm{~Hz}, 1 \mathrm{H})$, $7.57(\mathrm{t}, J=7.5 \mathrm{~Hz}, 1 \mathrm{H}), 7.45-7.17(\mathrm{~m}, 7 \mathrm{H}), 3.41$ (dd, $J=14.0,4.1 \mathrm{~Hz}, 1 \mathrm{H}), 3.17(\mathrm{dd}, J=17.0,7.6 \mathrm{~Hz}, 1 \mathrm{H})$, 3.01 (ddt, $J=11.5,7.7,4.0 \mathrm{~Hz}, 1 \mathrm{H}$ ), 2.86 (dd, $J=17.0,3.9 \mathrm{~Hz}, 1 \mathrm{H}), 2.67$ (dd, $J=14.0,10.4 \mathrm{~Hz}, 1 \mathrm{H}$ ).. ${ }^{13 \mathrm{C}}$ $\mathrm{NMR}\left(75 \mathrm{MHz}^{\mathrm{CDCl}} 3\right.$ ) $\delta$ 207.8, 153.6, 139.6, 136.5, 134.8, 128.9, 128.5, 127.4, 126.6, 126.3, 124.0, 48.9, 37.0, 32.2. (+ denotes residual methylene chloride, $\uparrow$ denotes silicone grease.) 

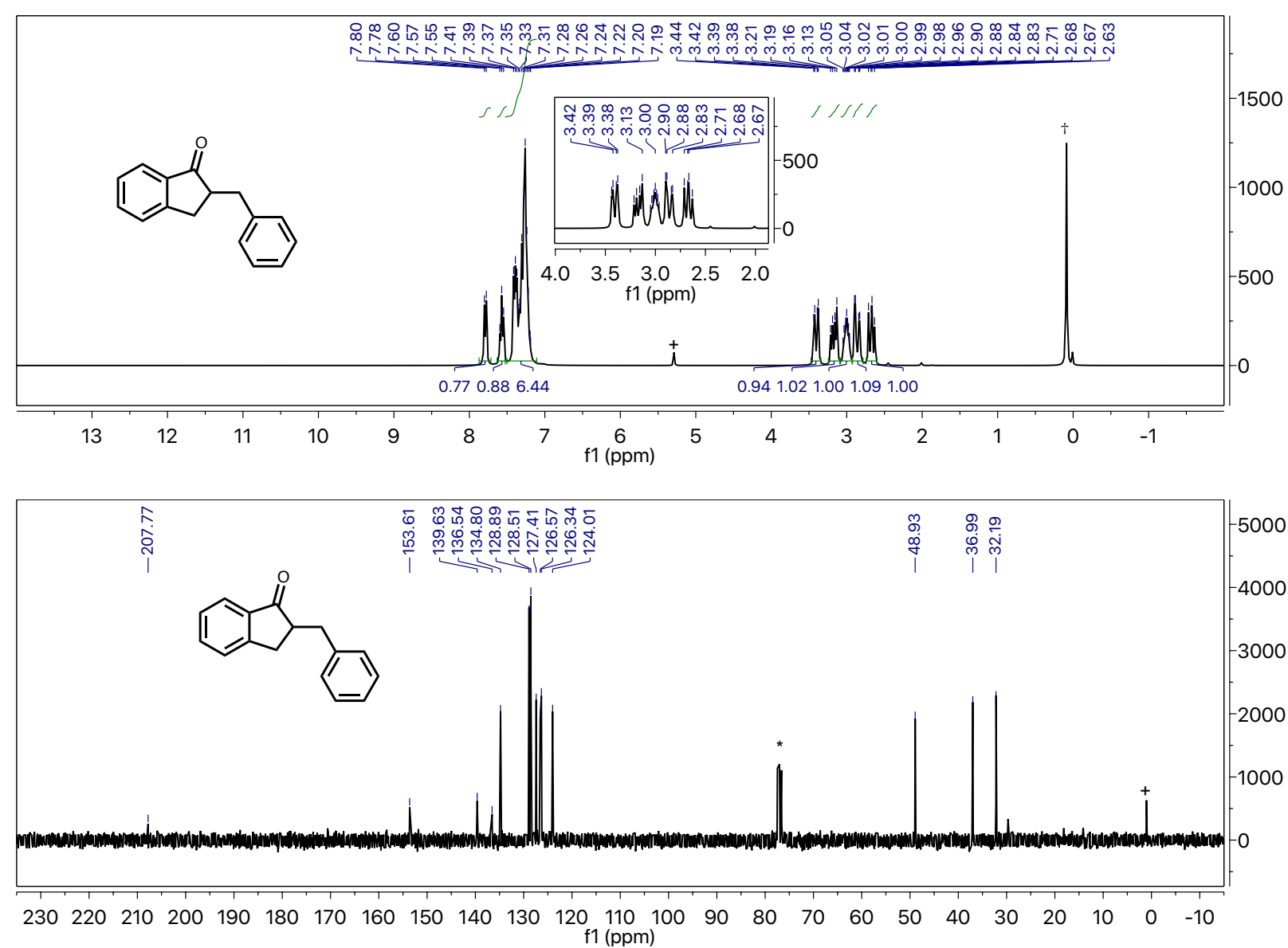

4-phenylbutan-2-one (1Oa). Yellow, viscous oil ( $75 \mathrm{mg}, 100 \%$ isolated yield) ${ }^{1} \mathrm{H} \mathrm{NMR}\left(300 \mathrm{MHz}, \mathrm{CDCl}_{3}\right)$ $\delta 7.33-7.27(\mathrm{~m}, 1 \mathrm{H}), 7.24-7.14(\mathrm{~m}, 4 \mathrm{H}), 2.90(\mathrm{t}, J=7.6 \mathrm{~Hz}, 2 \mathrm{H}), 2.76(\mathrm{t}, J=7.7 \mathrm{~Hz}, 2 \mathrm{H}), 2.14(\mathrm{~s}, 3 \mathrm{H}) .{ }^{13 \mathrm{C}}$ NMR (75 MHz, $\mathrm{CDCl}_{3}$ ) $\delta$ 141.0, 129.0, 128.5, 128.4, 128.3, 126.1, 45.2, 29.7.

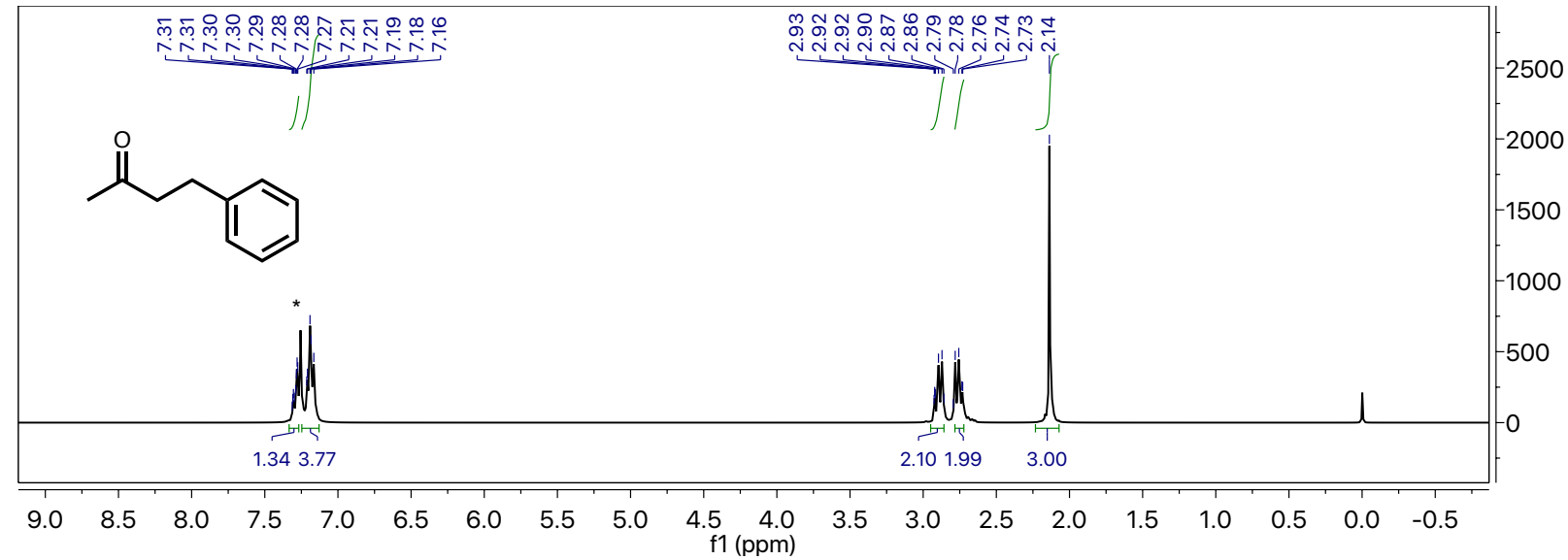




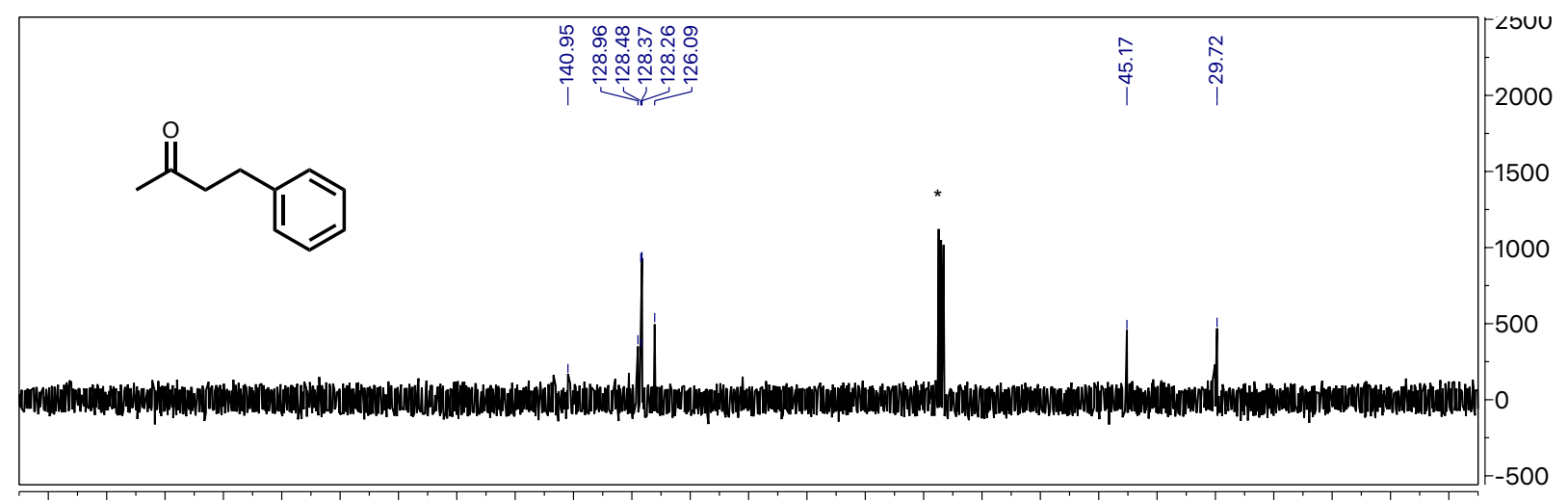

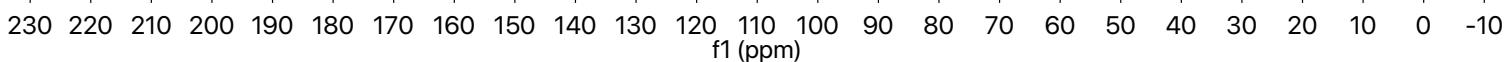

Pentan-2-one (11a). Clear, colorless oil (100\% conversion by NMR) ${ }^{1} \mathrm{H}$ NMR (300 MHz, Toluene-d8) $\delta$ $1.99-1.79(\mathrm{~m}, 2 \mathrm{H}), 1.67(\mathrm{t}, J=5.1 \mathrm{~Hz}, 3 \mathrm{H}), 1.56-1.35(\mathrm{~m}, 2 \mathrm{H}), 0.79(\mathrm{dd}, J=7.4,4.7 \mathrm{~Hz}, 3 \mathrm{H}) .{ }^{13 \mathrm{C}} \mathrm{NMR}(75$ MHz, Toluene-d8) $\delta$ 205.3, 44.8, 28.7, 17.0, 13.3.
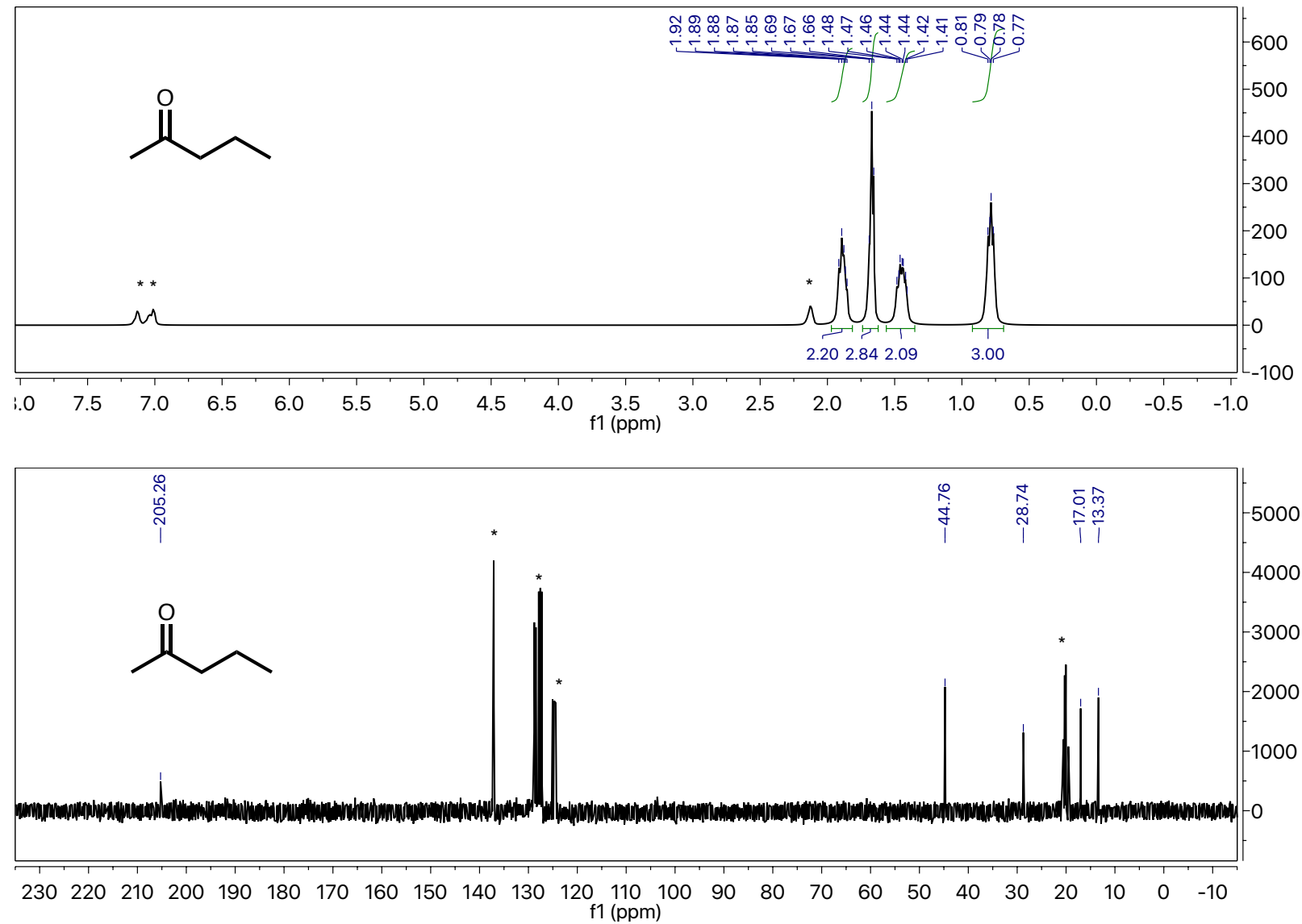

\section{References}

1. Chadwell, H. M.; Kohler, E. P. Org. Synth., 1922, 2, 1.

2. Luche, J-L.; Rodriguez-Hahn, L.; Crabbé, P.J. Chem. Soc. Chem. Commun. 1978, 601-602.

3. Testa, M. L.; Zaballos, E.; Zaragozá, R. J. Tetrahedron 2012, 68 (47), 9583-9591.

4 . Edwards, P. G.; Fallis, I. A.; Yong, B. S. Brit. UK Pat. Appl. GB 2378182 A 2003

5. Ito, M.; Osaku, A.; Kobayashi, C.; Shiibashi, A.; Ikariya, T. Organometallics, 2009, 28 (2), 390-393.

6. van Putten, R.; Uslamin, E. A.; Garbe, M.; Liu, C.; Gonzalez-de-Castro, A.; Lutz, M.; Junge, K.; Hensen, E. J. M.; Beller, M.; Lefort, L.; et al. Angew. Chemie Int. Ed. 2017, 56 (26), 7531-7534. 